\title{
Tipificação do HLA nos fenótipos alérgico e não alérgico da asma
}

\author{
Dissertação apresentada à Faculdade de \\ Medicina da Universidade de São Paulo para \\ obtenção de título de Mestre em Ciências \\ Programa de Alergia e Imunopatologia \\ Orientador: Prof Dr Pedro Giavina-Bianchi Junior
}

(Versão corrigida. Resolução CoPGr 6018/11 de 1 de novembro de 2011. A versão original está disponível na Biblioteca da FMUSP).

\section{São Paulo}




\section{Dados Internacionais de Catalogação na Publicação (CIP)}

Preparada pela Biblioteca da

Faculdade de Medicina da Universidade de São Paulo

Creprodução autorizada pelo autor

\section{Takejima, Priscila Megumi}

Tipificação do HLA nos fenótipos alérgicos e não alérgico da asma / Priscila Megumi Takejima. -- São Paulo, 2015.

Dissertação(mestrado)--Faculdade de Medicina da Universidade de São Paulo. Programa de Alergia e Imunopatologia.

Orientador: Pedro Giavina-Bianchi Junior.

Descritores: 1.Asma 2.Antígenos HLA-A 3.Antígenos HLA-B 4.Antígenos HLA-C 5.Genes classe I do complexo de histocompatibilidade (MHC) 6.Genes classe II do complexo de histocompatibilidade (MHC) 7.Fenótipo 8.Predisposição genética para doença 9.Herança multifatorial 10.Imunoglobulina E 11.Testes cutâneos 


\section{NORMATIZAÇÃO ADOTADA}

Esta dissertação está de acordo com as seguintes normas, em vigor no momento desta publicação:

Referências: adaptado de International Committee of Medical Journals Editors (Vancouver).

Universidade de São Paulo. Faculdade de Medicina. Divisão de Biblioteca e Documentação. Guia de apresentação de dissertações, teses e monografias. Elaborado por Anneliese Carneiro da Cunha, Maria Julia de A. L. Freddi, Maria F. Crestana, Marinalva de Souza Aragão, Suely Campos Cardoso, Valéria Vilhena. 3a ed. São Paulo: Divisão de Biblioteca e Documentação; 2011.

Abreviaturas dos títulos dos periódicos de acordo com List of Journals Indexed in Index Medicus. 


\section{DEDICATÓRIA}

Aos meus pais, Reinaldo e Suzana,

ao meu marido, Celio,

às minhas irmãs, Milka e Aline,

que com muito carinho e apoio, não mediram esforços

para que eu chegasse até esta etapa da minha vida. 


\section{AGRADECIMENTOS}

À Deus, pela fé, força e sabedoria para a concretização deste trabalho.

Ao meu orientador, Prof. Dr. Pedro Giavina-Bianchi, pela orientação, apoio e estímulo na realização deste trabalho, mas principalmente pelos seus ensinamentos e exemplo de um grande mestre.

Aos meus pais, Reinaldo e Suzana, exemplo de honestidade e persistência, sempre me incentivaram e apoiaram nesta caminhada.

Ao Celio, meu marido, por todo o carinho, cumplicidade e compreensão dispensados durante este período.

Às minhas irmãs, Milka e Aline, pela amizade, companheirismo e apoio para concretização deste sonho.

À Dra Rosana Agondi Câmara pelos ensinamentos, incentivo, apoio, orientações e exemplo de profissional de alta competência.

Ao Prof. Dr. Jorge Kalil, pelos ensinamentos e pela oportunidade de desenvolver este trabalho no Serviço de Imunologia Clínica e Alergia.

Ao Dr. Hélcio Rodrigues e demais integrantes do Laboratório de Histocompatibilidade do INCOR, pela receptividade e ensinamentos.

Ao Serafim Fidalgo, Maurício Freitas, Rosana Coutinho, Osvaldo Júnior e Leoni que com paciência e atenção colaboraram para a realização deste trabalho.

Aos meus avós, pelo apoio incondicional em todas as etapas da minha vida.

Às minhas queridas amigas, Marisa Ribeiro e Adriana $T$ Rodrigues, pela amizade e companheirismo. 
À Tania Joice, pela disponibilidade e atenção oferecida.

Ao Carlos Palma do Laboratório de Investigação Médica em Imunologia Clínica e Alergia- 60 (LIM-60) pela participação na realização de exames laboratoriais.

Ao Bernardo dos Santos pelo empenho na análise estatística.

À Dra Cristina Miuki Abe Jacob e Dr Gustavo Wandalsen pelas valiosas contribuições na banca de qualificação.

À Eleni, pela atenção oferecida.

Aos meus colegas do Serviço de Imunologia Clínica e Alergia do HC-FMUSP pelo carinho e companheirismo.

Aos pacientes que participaram deste estudo, pela preciosa colaboração. 
"Aprender é a única coisa da qual a mente nunca se cansa, nunca tem medo e nunca se arrepende"

Leonardo da Vinci 


\section{SUMÁRIO}

Lista de Figuras

Lista de Tabelas

Resumo

Summary

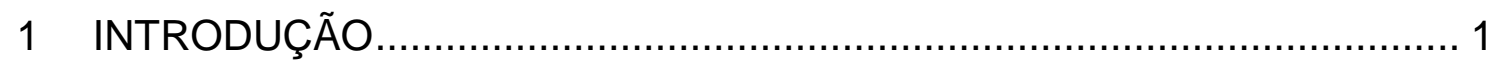

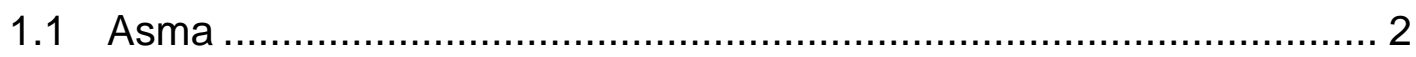

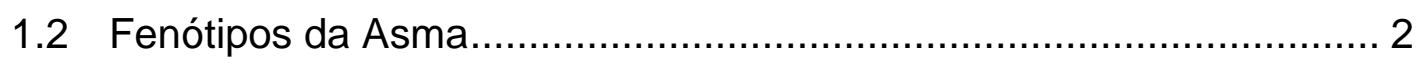

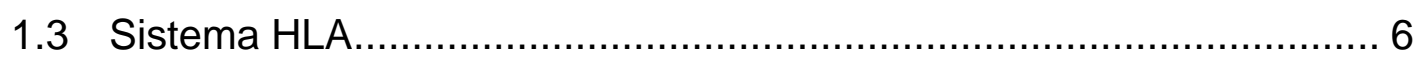

1.4 Sistema HLA e Asma ............................................................... 9

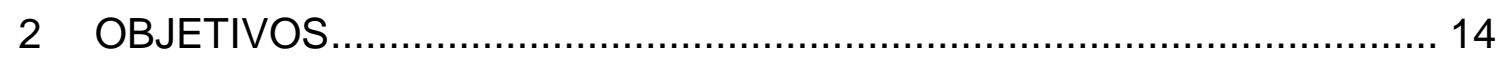

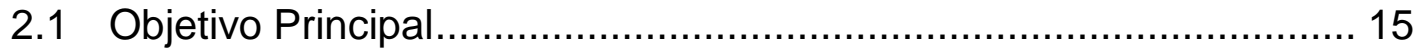

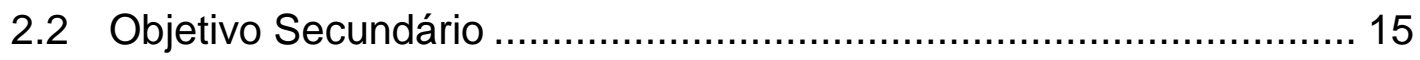

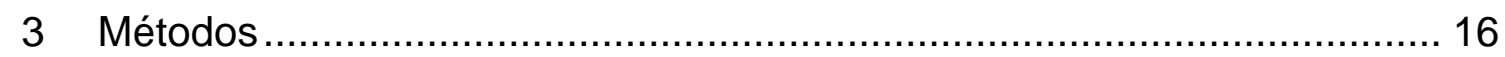

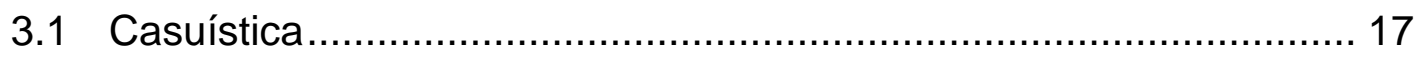

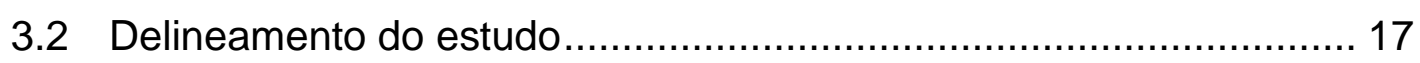

3.3 Descrição dos métodos .............................................................. 19

3.3.1 Teste cutâneo de puntura ................................................... 19

3.3.2 Dosagem sérica de IgE total .............................................. 20

3.3.3 Dosagem de IgE sérica específica........................................ 20

3.3.4 Prova de função pulmonar ................................................. 22

3.3.5 Tipificação HLA classe I e II ............................................... 22

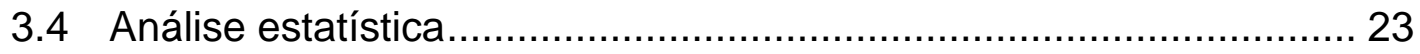

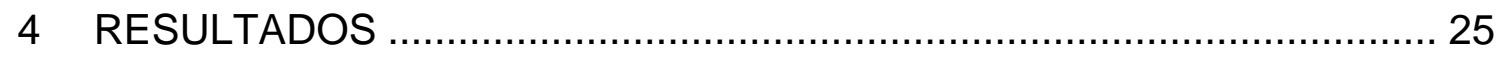

4.1 Caracterização dos participantes do estudo ..................................... 26

4.2 Tipificação dos alelos HLA ........................................................ 31

5 DISCUSSÃO

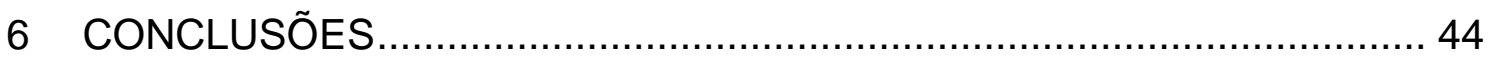

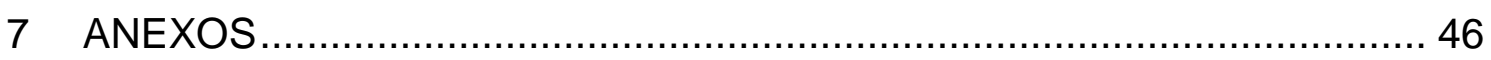

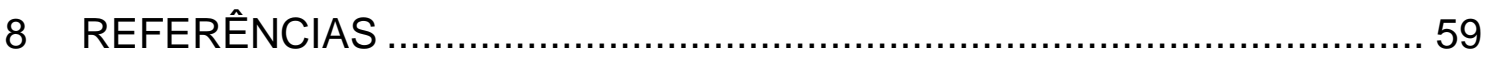




\section{LISTA DE FIGURAS}

Figura 1 - Estrutura da molécula MHC classe I (Abbas; 2008) ..................... 7

Figura 2 - Estrutura da molécula MHC classe II (Abbas; 2008).................... 8

Figura 3 - Resultado do teste cutâneo de puntura nos pacientes com asma alérgica............................................................................... 30

Figura 4 - Resultado da pesquisa de IgE sérica específica nos pacientes com asma alérgica.

Figura 5 - Análise por árvore de decisão do HLA dos três grupos participantes........................................................................... 34

Figura 6 - Análise por árvore de decisão dos grupos asma alérgica e não alérgica................................................................................ 35 


\section{LISTA DE TABELAS}

Tabela 1 - Alelos HLA classe I associados com asma ............................... 10

Tabela 2 - Alelos HLA classe II associados com asma ................................ 11

Tabela 3 - Características dos participantes do estudo ............................ 28

Tabela 4 - Distribuição de acordo com a cor da pele dos pacientes com asma alérgica e não alérgica................................................ 29

Tabela 5 - Dados dos pacientes dos grupos asma alérgica e não alérgica.... 29

Tabela 6 - Frequência dos antígenos HLA classe I e II e comparação entre os grupos.

Tabela 7 - Análise dos pacientes com asma com e sem história sugestiva de hipersensibilidade a AINES

Tabela 8 - Média dos níveis séricos de lgE e associação com HLA classe I e II 


\section{RESUMO}

Takejima PM. Tipificação do HLA nos fenótipos alérgico e não alérgico da asma [Dissertação]. São Paulo: Faculdade de Medicina, Universidade de São Paulo; 2015. 72p.

A asma é uma doença heterogênea caracterizada por um processo inflamatório crônico das vias aéreas inferiores que está associado ao desenvolvimento da hiperresponsividade brônquica e remodelamento da via aérea. Atualmente, a asma é considerada uma síndrome, ou ao menos uma doença com diversos fenótipos. Tradicionalmente, dois fenótipos são bem definidos pela clínica e exames subsidiários: asma alérgica e asma não alérgica. Eles são diferentes quanto á idade de início, apresentação clínica, história pessoal e familiar de atopia e resposta ao tratamento. Ao contrário da asma alérgica, cuja fisiopatologia está bem caracterizada, a etiologia e mecanismos envolvidos na asma não alérgica não estão bem elucidados. Algumas possibilidades incluem alergia desencadeada por antígenos desconhecidos (fungos), infecção persistente (Chlamydia trachomatis, Mycoplasma sp) e auto-imunidade. Estudos têm descrito em diferentes populações associações entre a asma e alelos/antígenos HLA classe I e II, mas os resultados têm sido inconclusivos. O objetivo deste estudo foi identificar possíveis associações do antígeno leucocitário humano (HLA) classe I (A, B, C) e II (DR, DQ, DP) em pacientes brasileiros com asma alérgica e não alérgica. Um total de 109 pacientes com o diagnóstico de asma (56 com asma alérgica e 53 com asma não alérgica) que estavam em acompanhamento no Serviço de Imunologia Clínica e Alergia do Hospital das Clínicas da Faculdade de Medicina da Universidade de São Paulo, e 297 controles (doadores falecidos de órgãos sólidos) tiveram seu sistema HLA classe I (A, B e C) e II (DR, DQ e DP) tipificado. Os pacientes também realizaram espirometria e coletaram sangue para a quantificação da imunoglobulina $E$ ( $\lg E$ ) sérica total e nível sérico de eosinófilos. Além disso, foram avaliados quanto à lgE específica para aeroalergenos através do teste cutâneo de puntura e a pesquisa da IgE sérica específica (ImmunoCAP). O grupo com asma alérgica foi constituído por pacientes que apresentavam resultado positivo para a pesquisa da IgE específica em ambos teste cutâneo de puntura e na investigação in vitro. E o grupo com asma não alérgica apresentava resultados negativos nos dois testes. A comparação do HLA classe I nos grupos estudados identificou frequência significativamente maior do HLA-B*42 e HLA-C*17 no grupo com asma alérgica, enquanto o HLA-B*48 estava estatisticamente associado com o fenótipo não alérgico. Na análise do HLA classe II, O HLA-DPA1*03 e HLA-DPB1*105 apresentou associação com os pacientes com asma alérgica. Concluindo, o estudo observou diferentes associações dos alelos HLA classe I e II com asma alérgica e não alérgica na população brasileira, a qual é caracterizada pela diversidade de origens e miscigenação. Porém, a predisposição genética para asma é poligênica e novos estudos em grandes populações são necessários para confirmar a associação do HLA como fator protetor ou causador da doença.

Descritores:1.Asma; 2.Antígenos HLA-A; 3.Antígenos HLA-B; 4.Antígenos HLA-C; 5.Genes classe I do complexo de histocompatibilidade (MHC); 6. Genes classe II do complexo de histocompatibilidade (MHC); 7.Fenótipo; 8.Predisposição genética para doença; 9.Herança multifatorial; 10.Imunoglobulina E; 11.Testes cutâneos. 


\section{SUMMARY}

Takejima PM. HLA typing in allergic and non-allergic asthma phenotypes [Dissertation]. São Paulo: "Faculdade de Medicina, Universidade de São Paulo"; 2015. 72p.

Asthma is a heterogeneous chronic inflammatory disease of lower airways associated with the development of bronchial hyperresponsiveness and airway remodeling. Currently, asthma is regarded as a syndrome or at least a disease with several phenotypes.Traditionally, two phenotypes of asthma have been defined according to clinical and laboratory features: allergic and non-allergic asthma. Each of them has distint age of onset, clinical presentation, personal and family history of allergy and response to therapy. In contrast to allergic asthma, which pathophysiology is well characterized, the etiology and mechanisms involved in non-allergic asthma remain unclear. Some possibilities include allergy triggered by unknow antigens (fungi), persistent infection (Chlamydia trachomatis, Mycoplasma sp) and autoimmunity. Studies have reported associations between asthma and HLA class I and II alleles/antigens in different populations, but the results have been inconclusive. The objective of this study was to identify possible associations of the human leukocyte antigens (HLA) class I (A, B and C) and II (DR, DQ and DP) in Brazilian patients with allergic and non-allergic asthma. A total of 109 patients with asthma (56 with allergic asthma and 53 with non-allergic asthma), who were being followed at the Service of Clinical Immunology and Allergy of the Hospital das Clínicas of the University of São Paulo Medical School, and 297 controls (deceased solid organ donors) had their HLA class I (A,B and C) and II (DR, DQ and DP) typing. Patients performed spirometry and had their blood drawn to measure total serum immunoglobulin $\mathrm{E}$ ( $\mathrm{lg} \mathrm{E}$ ) levels and eosinophil count. Furthermore, they were assessed for specific IgE to aeroallergens with skin prick test and serum tests (ImmunoCAP). The allergic asthma group was composed of patient presenting positive results for specific IgE in both skin prick test and in vitro assay. And the non-allergic asthma group had negative results in both tests. There were significantly higher frequencies of HLA-B*42 and HLA-C*17 in the allergic asthma group, whereas the HLA-B*48 was associated with the nonallergic group. Regarding HLA class II analysis, HLA-DPA1*03 and HLA DPB1*105 were associated with allergic asthma patients. In conclusion, the study identified different associations of HLA class I and II with allergic and nonallergic asthma in the Brazilian population, which is characterized by diversity of origins and miscegenation. However, the genetic predisposition of asthma is polygenic and new studies on large populations are needed to confirm the role of HLA as a protective or predisposing factor of disease.

Descriptors: 1.Asthma; 2.HLA-A antigens; 3.HLA-B antigens; 4.HLA-C antigens; 5.Genes, MHC class I; 6. Genes, MHC class II; 7. Phenotype; 8.Genetic predisposition to disease; 9.Multifactorial inheritance; 10.Immunoglobulin $\mathrm{E}$; 11.Skin Tests. 
1 INTRODUÇÃO 


\subsection{Asma}

A asma é doença inflamatória crônica das vias aéreas inferiores que está associada ao remodelamento e hiperresponsividade brônquica. Apresenta limitação ao fluxo aéreo variável que é reversível espontaneamente ou com tratamento e manifesta-se clinicamente por episódios de sibilância, aperto torácico, dispnéia e tosse, principalmente à noite ou pela manhã ao acordar. A prova de função pulmonar avalia e confirma a obstrução brônquica com reversibilidade e, junto com o quadro clínico, definem o diagnóstico da asma, além de aferirem sua gravidade (GINA; 2012).

Asma é uma doença de alta prevalência com uma estimativa de cerca de 300 milhões de indivíduos afetados no mundo (GINA; 2012). No Brasil, acomete cerca de 10 a $20 \%$ da população. Segundo o estudo ISAAC, a prevalência da asma entre escolares de 6 e 7 anos é de 24,3\% e entre adolescentes de 13 e 14 anos é de 19\% (Solé et al., 2006).

Atualmente a asma vem sendo considerada uma síndrome, ou ao menos uma doença com diversos fenótipos (Leung et al., 2004; Miranda et al., 2004; Green et al., 2010; Haldar et al., 2008; Moore et al., 2010). Nem todos pacientes têm a mesma evolução e se adequam completamente à abordagem proposta pelos consensos e, por isto, devem ser tratados de maneira individualizada.

\subsection{Fenótipos da Asma}

Muitos parâmetros têm sido utilizados para definir os fenótipos da asma. Fenótipos clínicos incluem aqueles relacionados ao nível de gravidade (leve, moderada, grave, quase fatal), frequência de exacerbações, resposta ao tratamento (difícil controle, cortico-dependente, cortico-resistente) e idade de início dos sintomas da doença (Wenzel, 2006). 
Outro parâmetro se baseia nos fatores desencadeantes da doença e incluem: exercício, alérgenos ambientais, alérgenos ocupacionais, medicamentos (como os anti-inflamatórios não esteroidais e os beta-bloqueadores) e alterações hormonais. O fenótipo também pode estar relacionado ao mecanismo imunofisiopatológico envolvido na doença (alérgica e não alérgica), ou ainda ao padrão de inflamação observado na via aérea (eosinofílico, neutrofílico ou paucicelular) (Wenzel, 2006).

Neste contexto, diversas classificações da asma em fenótipos foram descritas, estimulando novas linhas de estudo da doença com o objetivo de melhor caracterizar e abordar os pacientes. Não existe um consenso de quantos fenótipos da asma existem. Recentemente, na tentativa de aprimorar a identificação dos tipos da asma, a análise de clusters tem sido utilizada. Nesta análise os pacientes são agrupados em clusters de acordo com suas semelhanças. A metodologia é baseada em algoritmos matemáticos computadorizados que avaliam múltiplas variáveis, sem interferência e supervisão humana (Haldar et al.,2008; Henderson et al., 2008; Moore et al.,2010).

Os dois principais fenótipos da asma, com características nítidas e distintas, são a asma alérgica e a não alérgica. Rackemann, em 1947, foi o primeiro a classificar a asma utilizando os termos "asma extrínseca" e "asma intrínseca", dependendo da identificação ou não de um agente externo como causa da doença. O autor observou que na asma extrínseca o início dos sintomas da doença ocorre antes dos 30 anos de idade e na intrínseca após os 40 anos de idade.

Williams e Mc Nicol (1969) e Gregg (1977) caracterizaram a asma extrínseca em indivíduos atópicos, com início precoce dos sintomas (antes dos 20 anos de idade) e mais frequente em meninos. Em 1977, Gregg e Molina et al., identificaram um subtipo de asma que não se associava a atopia, iniciava após os 30 anos de idade e acometia principalmente mulheres. Posteriomente, os termos "asma extrínseca" e "asma intrínseca" foram substituidos pela terminologia asma alérgica e asma não alérgica, respectivamente (Johansson et al., 2001).

A asma alérgica tende a ter um início precoce, definido como início dos sintomas antes de 12 anos de idade (Miranda et al., 2004), evolução mais 
benigna, menor taxa de intolerância aos anti-inflamatórios não esteroidais (AINES) e normalmente vem associada a história pessoal e familiar de outras doenças atópicas (Sibbald e Turner-Warwick,1979; Miranda et al.,2004; Moore et al.,2010). Suas exacerbações estão caracteristicamente relacionadas à exposição aos aeroalérgenos. Cerca de $80 \%$ dos quadros de asma na infância e mais de 50\% das asmas em adultos são alérgicas (Johansson et al., 2004).

Os pacientes com asma alérgica apresentam aumento sérico de imunoglobulina $\mathrm{E}$ ( $\lg E$ ) total e presença de lgE específica (Hallstrand et al., 2001). Esta última pode ser detectada por exames in vivo (testes cutâneos de leitura imediata: teste cutâneo de puntura e intradérmico) e in vitro (ImmunoCAPß). Em alguns casos, a lgE específica só é detectada no local onde está ocorrendo a doença alérgica (Platts-Mills, 1979 e Mosbech et al., 1987), processo denominado alergia local.

Em ambos os fenótipos, geralmente existe uma inflamação eosinofílica das vias aéreas (Wardaw et al., 2000), porém pode-se observar uma maior ocorrência de infiltração de neutrófilos na asma não alérgica. Estudos têm detectado um aumento significativo do número de neutrófilos no escarro induzido de enfermos com asma grave em relação aos que apresentavam asma leve e a indivíduos normais sem doença (Jatakanon et al., 1999). Os níveis de interleucina 8 e mieloperoxidase de neutrófilo estão aumentados nestes pacientes. A inflamação neutrofílica também foi observada nas exacerbações agudas da doença e na asma fatal de rápida evolução (Sur et al., 1993; Fahy et al., 1995; Lamblin et al., 1998).

Entretanto, a asma alérgica que normalmente tem evolução mais benigna, também pode ser grave e de difícil controle. O estudo TENOR (2005) mostrou que, na infância, o nível de lg $\mathrm{E}$ é um marcador de gravidade.

A alergia respiratória é um exemplo de reação de hipersensibilidade do tipo I, na qual o alérgeno é apresentado ao linfócito T que mediará uma resposta imune tipo Th2, com formação de anticorpos do isotipo E (Romagnani, 1994; Kourilsky et al., 2001; Giavina-Bianchi et al., 2008). A lgE sintetizada se liga a receptores de alta afinidade em basófilos e mastócitos. Após esta etapa de sensibilização, em contatos subseqüentes do organismo com o alérgeno, este irá se unir a $\lg E$ da superfície das células, que serão ativadas. Na reação de 
hipersensibilidade do tipo I, a ocorrência de duas fases é bem característica, com uma fase imediata em decorrência da desgranulação de mastócitos e basófilos e uma fase tardia devido ao recrutamento por quimiotaxia de outras células, como os eosinófilos, que migram para o sítio inflamatório. Quando o processo se torna crônico, há uma superposição destas fases (Busse et al., 1993; Santing et al., 1994).

$\mathrm{Na}$ verdade, a resposta imune é uma rede, com a atuação de diversas células que se comunicam pela secreção de citocinas e expressão de moléculas de adesão. Não existe uma única célula ou um único mediador responsável pela resposta alérgica. Estudo recente sugere, inclusive, que a asma alérgica desencadeada por resposta Th2 pode ocorrer mesmo sem a participação do anticorpo lgE (Agondi et al.,2010).

Por outro lado, a asma não alérgica tem sido descrita como uma doença de início tardio, ou seja, os sintomas têm início com 12 ou mais anos de idade (Miranda et al., 2004). Ocorre predominantemente em indivíduos do sexo feminino e mais frequentemente está associada a polipose nasal (RomanetManent et al., 2002) e hipersensibilidade aos anti-inflamatórios não esteroidais (Settipane et al., 1977; Charpin et al., 2003). A história pessoal e familiar de atopia é pouco frequente neste fenótipo (Sibbald et al., 1979; Miranda et al., 2004; Moore et al., 2010). Alguns trabalhos sugerem que este fenótipo apresenta um declínio maior da função pulmonar do que a asma alérgica (Ulrik et al.,1992; Romanet-Manent et al., 2002; Miranda et al., 2004).

Ao contrário da asma alérgica, cuja fisiopatogenia está bem caracterizada, a etiologia e os mecanismos envolvidos na asma não alérgica não estão elucidados. A doença poderia ser desencadeada por reações de hipersensibilidade a alérgenos não identificados, como os fungos, por infecções recorrentes ou persistentes (Macek et al.,1994), ou ainda por autoimunidade (Leopold et al., 1965; Lidor et al., 1980; Szczeklik et al.,1995; Naham et al., 2001; Comi et al., 2007)

Um possível mecanismo envolvido na fisiopatogenia da asma não alérgica é a inflamação e fibrose da parede da via aérea em resposta a infecções, como o Mycoplasma pulmonis (Mclntosh et al.,1992) e o adenovírus, principalmente em crianças (Macek et al., 1994). Os episódios de infecções 
recorrentes ou persistentes por Chlamydia pneumoniae também poderiam desencadear alterações estruturais na via aérea e limitação persistente ao fluxo aéreo (Brinke et al., 2001).

Outro mecanismo que pode estar relacionado à fisiopatologia da asma não alérgica é a autoimunidade, possivelmente desencadeada após infecção viral de vias aéreas (Menz et al.; 1998). O teste do autossoro pode ser positivo em pacientes com asma não alérgica, sugerindo uma base autoimune para a doença (Comi et al., 2007).

A classificação da asma nos tipos alérgico e não alérgico não é meramente conceitual, mas tem implicações no prognóstico e tratamento. Por exemplo, o controle ambiental é feito de maneira diferente, assim como o anticorpo anti-lgE (Pillai et al.; 2011) e a imunoterapia só estão indicados na asma alérgica (Lockey, 2014).

Vários fenótipos e modelos de classificação da asma foram propostos, mas não há concordância em um sistema único, consistente, que englobe e diferencie os diversos padrões da síndrome. Há um alto grau de subjetividade e pouco embasamento científico na descrição de alguns fenótipos.

Concluindo, a asma é uma doença heterogênea, refletindo processos fisiopatológicos distintos que provavelmente resultam de diferentes exposições ambientais e causam diferentes manifestações clínicas, com respostas terapêuticas e prognósticos variados. A medicina personalizada é baseada no princípio de que estímulos externos (ambiente) induzem diversas manifestações clínicas (fenótipos) mediadas por processos fisiopatológicos distintos (endótipos) em diferentes indivíduos (genótipos) (Giavina-Bianchi, 2015). Portanto, o médico precisa individualizar o tratamento do paciente. O próximo passo é definir quais são os fenótipos realmente relevantes.

\subsection{Sistema HLA}

O sistema HLA (do inglês, Human Leukocyte Antigen) está localizado no braço curto do cromossomo 6 humano e sua função fisiológica é apresentar peptídeos derivados de antígenos proteicos para os linfócitos T específicos. 
Além de sua função na resposta imune, tem influência no sucesso do transplante de órgãos e está associado com diversas doenças autoimunes e infecciosas (Agrawall et al.; 2002). Os genes do sistema HLA são os mais polimórficos do genoma humano.

A região é didaticamente dividida em classes:

- Classe I: codifica as moléculas HLA-A, HLA-B e HLA-C. Encontra-se presente em praticamente todas as células nucleadas e tem como função apresentar peptídeos para os linfócitos T citotóxicos (CD8).

- Classe II: codifica os antígenos HLA-DR, HLA-DQ e HLA-DP. Estão expressas na superfície de células apresentadoras de antígenos e apresentam os peptídeos para os linfócitos T auxiliares (CD4).

Os genes da classe I estão localizados na porção mais telomérica do Complexo HLA. As moléculas da classe I são formadas por 2 cadeias polipeptídicas ligadas de forma não covalente. Uma cadeia a (cadeia pesada) que é codificada pelo $\mathrm{MHC}$ e a proteína $\beta 2$ - microglobulina que não é codificada pelo MHC (Figura 1).

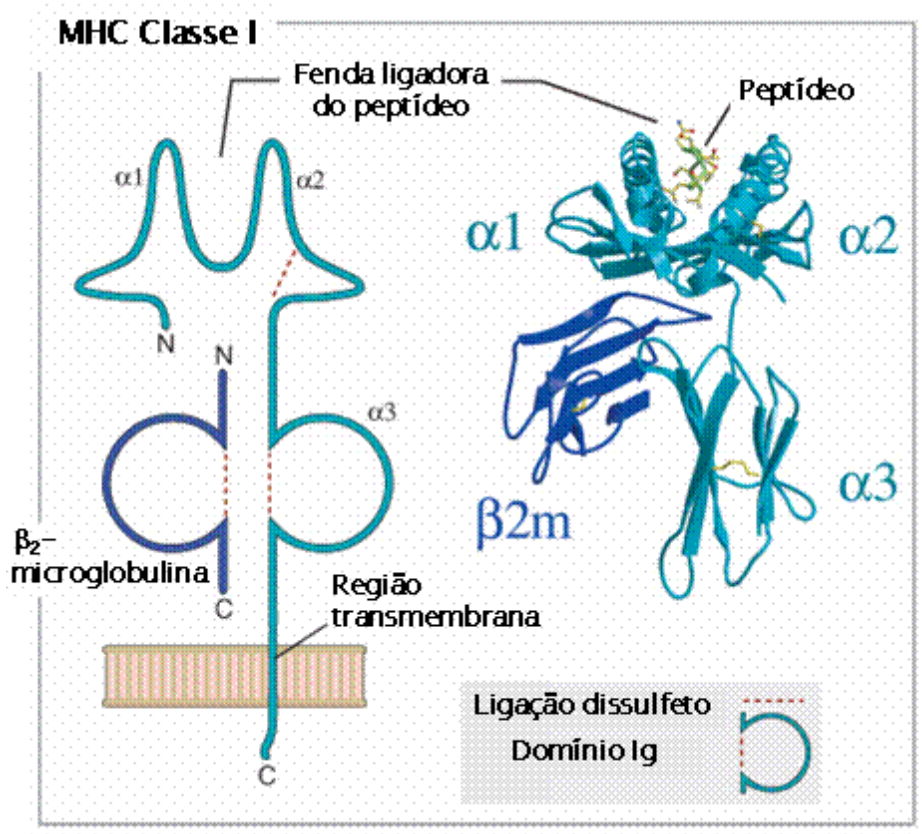

Figura 1 - Estrutura da molécula MHC classe I (Abbas; 2008) 
O polimorfismo das moléculas HLA classe I está localizado nos domínios a1e a2 que formam uma fenda de ligação onde o peptídeo se liga para ser apresentado para as células T. O domínio a 3 é constante e possui o local de ligação para o receptor CD8 do linfócito $T$.

As moléculas HLA classe I são responsáveis pela apresentação de antígenos intracelulares como os vírus. Os proteassomas degradam as proteínas citosólicas, formando peptídeos que se ligam às moléculas de classe I. A TAP que é uma molécula transportadora carreia os peptídeos do citoplasma para o interior do retículo endoplasmático. Dímeros do $\mathrm{MHC}$ classe I e a $\beta 2$ microglobulina se fixam ao TAP. Com isso, as moléculas classe I capturam os peptídeos e são transportadas para a superfície celular onde apresentam os antígenos para os linfócitos T CD8 que eliminam a célula.

As moléculas HLA classe II estão situadas na região centromérica do complexo HLA. Cada molécula consiste em duas cadeias, $\alpha$ e $\beta$ (Figura 2) que são codificadas por genes MHC. O polimorfismo nas regiões aminoterminais a1 e $\beta 1$ acomoda peptídeos contendo de 10 a 30 resíduos. No domínio $\beta 2$ esta o local de ligação para o co-receptor CD4 da célula T.

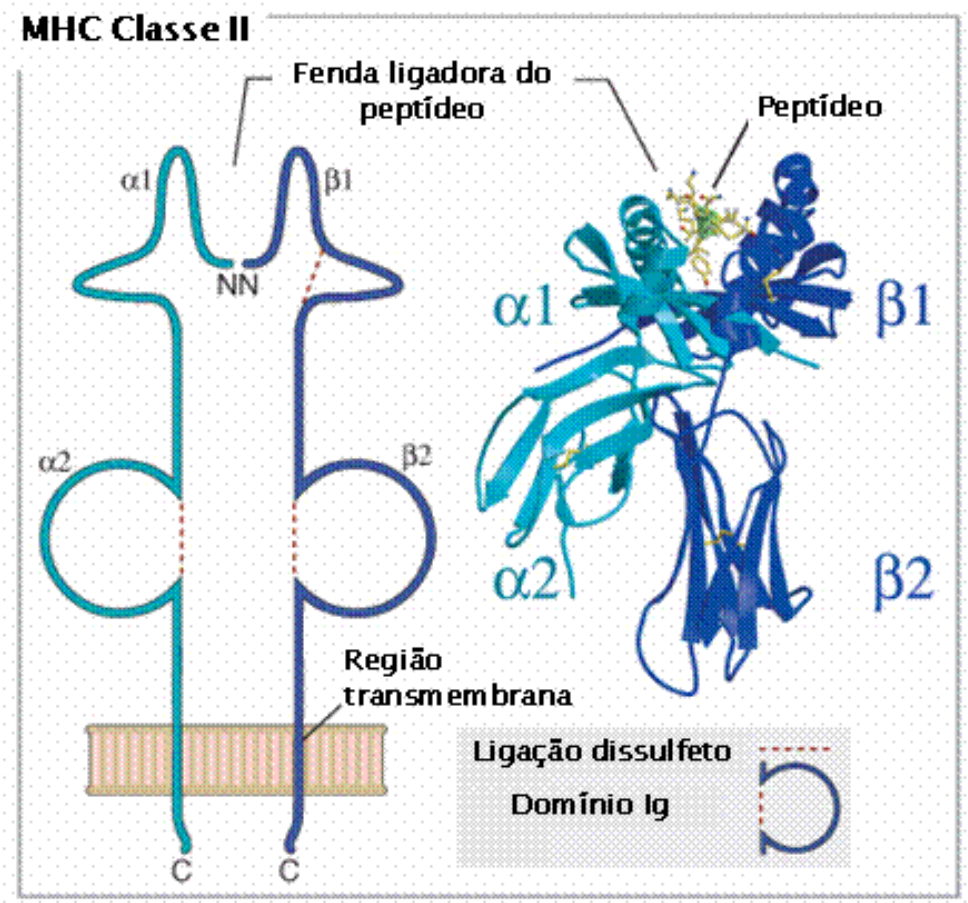

Figura 2 - Estrutura da molécula MHC classe II (Abbas; 2008) 
As moléculas classe II são expressas nos linfócifos $B$, macrófagos e células dendríticas. Os microorganismos ou proteínas microbianas são interiorizadas nos endossomos ou fagossomos onde são degradas por enzimas proteolíticas. Cada molécula classe II recém sintetizada no retículo endoplasmático é transportada para as vesículas endossomicas e ligada a uma proteína chamada de cadeia constante (CLIP) que se liga à sua fenda. O endossomo possui uma proteína chamada DM que remove o CLIP da fenda de ligação do peptídeo da molécula MHC. Os peptídeos gerados a partir das proteínas extracelulares endocitada se ligam à fenda e formam um complexo que migra até a superfície da célula onde será reconhecido pelas células T CD4.

Uma terceira região genômica (classe III), localizada entre os grupos de genes classe I e II, carrega numerosos genes não relacionados ao $\mathrm{MHC}$, codifica vários componentes do sistema complemento para três citocinas estruturalmente relacionadas, o fator de necrose tumoral, a linfotoxina- a e a linfotoxina- $\beta$; e para algumas proteínas do choque térmico.

\subsection{Sistema HLA e Asma}

Muitos estudos têm sido realizados na tentativa de elucidar a fisiopatologia da asma, identificar grupos de risco e desenvolver novos tratamentos. Os alelos do sistema HLA classe I (Tabela 1) e classe II (Tabela 2) têm sido identificados como candidatos, porém sua influência no desenvolvimento desta doença permanece obscura. 
Tabela 1 - Alelos HLA classe I associados com asma

\begin{tabular}{lll}
\hline \multicolumn{1}{c}{ Fenótipos da Asma } & HLA classe I & Referência \\
\hline Asma alérgica com deficiencia IgA & $\uparrow$ HLA-A1/ B8 & Ostergaard et al. 1979 \\
Asma alérgica com polipose nasal & $\uparrow$ HLA-A1/ B8 & Moloney et al. 1980 \\
Asma alérgica & $\uparrow$ HLA-B5 & Huang et al 1981 \\
Asma alérgica & $\uparrow$ HLA-Bw61 & Wang et al. 1988 \\
Asma de acordo com idade de início & $\uparrow$ HLA-A10 e $\downarrow$ HLA-B5 (antes 17 anos de idade) & Apostolakis et al. 1996 \\
& $\uparrow$ HLA-AB8 (após 17 anos de idade) & \\
Asma alérgica e níveis séricos da lgE & $\uparrow$ HLA-B8 & Ivkovic-Jurekovic et al. 2011 \\
\hline
\end{tabular}


Tabela 2 - Alelos HLA classe II associados com asma

\begin{tabular}{|c|c|c|}
\hline Fenótipos da Asma & HLA classe II & Referência \\
\hline Asma alérgica & HLA-DR2 (associação positiva); HLA-DR4 (associação negativa) & Hsieh et al.;1991 \\
\hline Asma alérgica & $\downarrow$ HLA-DPB $1 * 0401$ & Caraballo et al. 1991 \\
\hline Asma alérgica & $\uparrow H L A-D R B 1{ }^{*} 11: 01$, HLA-DQA1*05:01, HLA-DQB1*03:01 & Lara-Marquez et al. 1999 \\
\hline \multirow[t]{2}{*}{ Asma alérgica } & $\uparrow H L A-D Q A 1 * 0104$ e HLA-DQB1*0201 & \multirow[t]{2}{*}{ Gao et al. 2003} \\
\hline & $\downarrow$ HLA-DQA $1{ }^{*} 0301$ e HLA-DQB $1{ }^{*} 0301$ & \\
\hline Asma sensibilizada por & HLA-DRB1*01 DQB1*05:01 & Torio et al. 2003 \\
\hline \multicolumn{3}{|l|}{ Artemisia vulgaris } \\
\hline Asma alérgica (ácaros) & $\uparrow$ HLA-DRB $1 * 04, \uparrow$ HLA-DQA ${ }^{*} 0301$ & Parapanissiou et al, 2005 \\
\hline Asma na criança & HLA-DRB $1^{*} 03$ & Juhn et al. 2006 \\
\hline Asma alérgica (sensibilização à & HLA-DQB1*0609 DRB1*13 e HLA-DQB1*0501 DRB1*01 & \multirow[t]{2}{*}{ Munthe-Kaas et al. 2007} \\
\hline Artemisia vulgaris e bétula & (Artemisia vulgaris) HLA-DQB1*0603 DRB1*13( bétula) & \\
\hline Asma sensibilizada por Alternaria & $\downarrow$ HLA-DQB1*03 & Knutsen et al. 2010 \\
\hline Asma de difícil controle & HLA-DR/DQ & Li et al. 2010 \\
\hline Asma de início na idade adulta & HLA-DQ & Moffatt et al. 2010 \\
\hline Asma & HLA-DPA $1{ }^{*} 0201$ e HLA-DPB $1{ }^{*} 0901$ & Noguchi et al. 2011 \\
\hline
\end{tabular}


Em 1971, Thorsby et al. demostraram um aumento sem significância estatística da frequência do haplótipo HLA A1-B8 em crianças com asma não alérgica. $O$ mesmo haplótipo também foi associado à asma em crianças com deficiência de IgA (Ostergaard e Ericksen.;1979) e com polipose nasal (Moloney e Oliver.;1980).

Brostoff et al. (1976) relataram um aumento da frequência de Bw6 nos pacientes com asma não alérgica e sugeriram um modelo de herança recessiva. Porém, o estudo incluiu um pequeno número de participantes e uma avaliação do padrão de herança sem estudo familiar é discutível.

Turton et al. (1979) avaliaram a associação dos antígenos HLA classe I em pacientes com asma alérgica, asma não alérgica e aspergilose broncopulmonar alérgica, porém não encontraram associação em nenhum dos três grupos estudados. Resultado semelhante foi encontrado num estudo que envolveu indivíduos com asma alérgica com sensibilização por Alternaria e asma não alérgica (Flaherty et al. 1980).

Estudo realizado na China mostrou uma frequência maior do HLA-B5 e menor do HLA-B17 em crianças com asma (Huang et al. 1981). Em outro estudo chinês, na Manchúria, o HLA-Bw61 apresentou associação com asma alérgica (Wang et al.;1988), sugerindo que diferentes antígenos HLA podem estar envolvidos na patogenese da asma. Hsieh et al. (1991) estudaram crianças chinesas com asma sensibilizadas para poeira doméstica e com elevado nível sérico de $\operatorname{lgE}$ e observaram associação positiva com HLA-DR2 e negativa com HLA-DR4.

Parapanissiou et al. (2005) mostraram que os antígenos HLA-DRB1*04 e DQA1 *0301 são importantes fatores de risco para o desenvolvimento da asma em crianças sensibilizadas aos ácaros na Grécia. Por outro lado, um estudo realizado na França relatou uma menor frequencia do antígeno HLA-DRB1*04 em pacientes com asma alérgica (Aron $Y$ et al. 1996).

Muitas pesquisas chinesas observaram associação dos alelos HLA-DQ e HLA-DR com suscetibilidade para o desenvolvimento da asma (Gao et al., 1998; Wang et al., 1999; Guo et al., 2001). Entretanto, Li et al. (1995) não identificaram associações entre HLA classe II e pacientes com asma no sul da China. 
Li et al. (2010) relataram a associação dos genes RAD50, IL13, HLA-DQB1 e HLA-DRB1 em pacientes caucasianos com asma grave ou asma de difícil controle. Martyn et al. (2010) observaram que crianças com HLA-DRB1*11 e DQB1*0301 apresentavam uma progressão mais lenta do início dos sintomas para o diagnóstico de asma.

Em 2012, Lasky-Su et al. publicaram os resultados de um estudo de associação ampla do genoma (GWAS) em pacientes com asma, identificando polimorfismo na região próxima ao HLA-DQA1 em adultos. O maior GWAS realizado em asma foi o GABRIEL consortium que envolveu 10365 pacientes e 16110 controles e identificou associações abrangendo IL33, IL1RL1/IL18R1, HLA-DQ, SMAD3, IL2RB e o locus 17q21 (Moffatt et al., 2010).

O antígeno leucocitário humano G (HLA-G) é uma molécula não clássica do sistema MHC (Complexo Maior de Histocompatibilidade) e apresenta atividade importante na tolerância materna para diferentes tecidos fetais, além de papel regulatório no transplante e na patogênese de doenças inflamatórias (White et al.; 2012). Um trabalho com crianças atópicas com asma descreveu níveis aumentados deste HLA na comparação com grupo controle saudável (Tahan et al.; 2006).

Em 2010, Ciprandi et al. relataram que crianças com rinite alérgica ou asma alérgica também apresentavam nível sérico aumentado do HLA-G quando comparadas com o grupo controle. Resultado similar foi observado em adultos com asma e rinite alérgica, sugerindo que o HLA-G poderia ser um marcador de doenças alérgicas (Ciprandi et al.; 2014). 
2 OBJETIVOS 


\subsection{Objetivo Principal}

- Identificar possíveis associações entre o sistema HLA e os fenótipos alérgico e não alérgico da asma.

\subsection{Objetivo Secundário}

- Avaliar e caracterizar o perfil clínico e laboratorial dos fenótipos alérgico e não alérgico da asma. 
3 Métodos 


\subsection{Casuística}

Estudo observacional prospectivo que comparou a frequência dos diferentes tipos de HLA classe I e II em pacientes com asma alérgica e não alérgica.

Os pacientes do estudo foram selecionados no ambulatório de Asma do Serviço de Imunologia Clínica e Alergia do Hospital das Clínicas da Faculdade de Medicina da Universidade de São Paulo (HC-FMUSP) e, após receberem informações sobre a pesquisa, assinaram o Termo de Consentimento Livre e Esclarecido (Anexo 1). O estudo foi aprovado pela Comissão de Ética para Análise de Projetos de Pesquisa (CAPPesq) da Diretoria Clínica do Hospital das Clínicas da Faculdade de Medicina da Universidade de São Paulo, protocolo número 0774/10 (Anexo 2).

Todos os pacientes incluídos no estudo tinham diagnóstico de asma confirmado pelos critérios da GINA (Global Initiative for Asthma, 2012), com história clínica compatível e pelo menos uma prova de função pulmonar evidenciando obstrução brônquica com reversibilidade. Os participantes deveriam ter idade maior ou igual a 18 anos e menor ou igual a 75 anos, nunca ter fumado, ausência de qualquer outra doença pulmonar associada (inclusive asma ocupacional) e capacidade cognitiva que permitisse a participação no estudo. Foram excluídos os pacientes que apresentavam doenças cutâneas ou que usavam medicações que interferissem com a realização do teste cutâneo de puntura.

\subsection{Delineamento do estudo}

Os pacientes foram avaliados prospectivamente, sendo interrogados quanto aos fatores desencadeantes de exacerbações, idade de início dos sintomas da asma, história pessoal e familiar de doenças atópicas (asma, 
rinite, conjuntivite alérgica e dermatite atópica), história sugestiva de reação de hipersensibilidade aos anti-inflamatórios não hormonais e medicamentos utilizados no tratamento para o controle da doença. Os prontuários dos pacientes foram revistos em busca de informações relevantes. Além disso, foram coletados dados referentes à cor da pele (ou raça) conforme utilizado pelo Instituto Brasileiro de Geografia e Estatística (IBGE) onde a própria pessoa se classifica dentro de cinco categorias: branca, preta, amarela (oriental), parda (mulata, cabocla, cafuza, mameluca ou mestiça de preto com outra cor ou raça), indígena (IBGE, 2011).

Para caracterizar o diagnóstico de atopia, todos os pacientes com asma foram submetidos à pesquisa de sensibilização a aeroalérgenos relevantes na cidade de São Paulo. Foram realizadas provas in vivo (teste cutâneo de puntura) e in vitro (dosagem sérica de lgE específica).

O teste cutâneo de puntura foi realizado para os seguintes alérgenos: Dermatophagoides pteronyssinus, Blomia tropicalis, Cladosporium herbarum, Alternaria alternata, Penicillium notatum, Aspergillus fumigatus, Canis familiaris, Felis domesticus, Lolium perene, Periplaneta americana e Blatella germânica. A histamina $(10 \mathrm{mg} / \mathrm{ml})$ foi utilizada como controle positivo e a solução salina $0,9 \%$ como controle negativo. O teste foi considerado positivo quando apresentava o diâmetro médio (média entre o maior diâmetro da pápula e o diâmetro perpendicular a este) maior do que $3 \mathrm{~mm}$ em relação ao diâmetro médio do controle negativo (Demoly et al.,2003).

Os pacientes foram submetidos à coleta de sangue venoso periférico para pesquisa do nível sérico de $\lg \mathrm{E}$ total, contagem dos eosinófilos sanguíneos, IgE sérica específica utilizando o ImmunoCAP System (Pharmacia Diagnostics, Uppsala, Suécia) para Blomia tropicalis, fungos (Penicillium nonatum, Cladosporium herbarum, Aspergillus fumigatus e Alternaria alternata), poeira doméstica e epitélio de animais (cão, gato, vaca e cavalo). Os valores da lgE específica foram considerados positivos quando iguais ou maiores que $0,35 \mathrm{KU} / \mathrm{L}$.

Os pacientes foram divididos em dois grupos conforme história clínica e os resultados do teste cutâneo de puntura e da dosagem sérica de lgE específica realizados. Apenas os pacientes com as pesquisas de sensibilização 
in vivo e in vitro concordantes (duplamente positivas ou negativas) foram analisados, os demais sendo excluídos do estudo.

- Grupo Asma Alérgica: pacientes com asma, com história de desencadeamento de crises por aeroalérgenos, com resultados do teste cutâneo de puntura positivo para pelo menos um dos alérgenos testados e lgE sérica específica maior ou igual a $0,35 \mathrm{KU} / \mathrm{L}$ para qualquer alérgeno estudado.

- Grupo Asma não Alérgica: pacientes com asma, sem história de desencadeamento de crises por aeroalérgenos, com resultados do teste cutâneo de puntura negativo e IgE sérica específica menor ou igual a 0,35 $\mathrm{KU} / \mathrm{L}$ para todos os alérgenos testados.

Um terceiro grupo formado por doadores falecidos de órgãos sólidos foi utilizado como grupo controle na análise do HLA. Há um banco de dados com informações do HLA destes indivíduos que tiveram suas amostras de DNA tipificadas no Laboratório de Imunologia de Transplantes do Instituto do Coração (INCOR) do Hospital das Clínicas da Faculdade de Medicina da Universidade de São Paulo, no período de 01/01/2011 e 21/03/2012.

A tipificação do HLA classe I (A, B, C) e II (DR, DQ, DP) em baixa/média resolução foi realizada para todos os participantes dos três grupos envolvidos no estudo. A frequência dos alelos do sistema HLA foi analisada comparandose os grupos do estudo e segundo as características clínicas dos pacientes.

\subsection{Descrição dos métodos}

\subsubsection{Teste cutâneo de puntura}

O teste cutâneo de puntura ou prick test demonstra a sensibilização in vivo, ou seja, presença de $\lg \mathrm{E}$ específica para determinado alérgeno. Os testes foram realizados em duplicata na superfície volar do antebraço onde foi aplicada uma pequena gota de cada extrato dos alérgenos testados e das soluções de controle positivo (histamina $10 \mathrm{mg} / \mathrm{mL}$ ) e negativo (solução salina $0,9 \%$ ). Os extratos alergênicos da indústria farmacêutica IPI/ASAC 
(International Pharmaceutical Immunology/ ASAC Laboratory Brasil) eram padronizados e purificados.

Cada gota foi colocada com uma distância entre elas de dois centímetros para evitar interferências e reações falso-positivas. A pele foi perfurada com lancetas estéreis e descartáveis Alergoprick®. A leitura do teste foi realizada após 15 minutos e para a graduação do teste cutâneo foi utilizada uma régua milimetrada onde foram medidos o maior diâmetro da pápula e o diâmetro perpendicular a este.

\subsubsection{Dosagem sérica de IgE total}

A quantificação da imunoglobulina $E$ sérica total foi realizada por nefelometria através da utilização de kits padronizados (Dade Behring/Siemens, Deerfield, USA). O valor de corte para níveis elevados da lgE foi fixado em $>100 \mathrm{UI} / \mathrm{mL}$. Foi realizado no Laboratório de Bioquímica Clínica da Divisão do Laboratório Central do HC-FMUSP.

\subsubsection{Dosagem de IgE sérica específica}

$\mathrm{Na}$ coleta de sangue venoso foi utilizado scalp número 21 ou 23, com uso de luvas e garrote. O material foi coletado em tubos não heparinizados. O sangue foi centrifugado, o soro foi armazenado em alíquotas de 1,5 mL e encaminhada para o Laboratório de Investigação Médica em Imunologia e Alergia -60 (LIM-60) para a realização da dosagem da lgE sérica específica.

A pesquisa da IgE sérica específica é um ensaio quantitativo in vitro que mede a $\lg E$ especifica presente no soro do paciente para um determinado alérgeno. $\mathrm{O}$ método ImmunoCAP® foi utilizado neste estudo para mensurar a IgE específica para os alérgenos selecionados.

A tecnologia ImmunoCAP® utiliza um imunoensaio do tipo sanduíche (ELISA) e o aparelho é programado para distribuir as amostras e os reagentes, processando todos os passos desde incubação, lavagem, medição do cálculo e a impressão dos resultados. O aparelho automatizado UniCAP 250 foi utilizado para realização das dosagens. 
O componente fundamental do teste é a fase sólida que consiste em um derivado de celulose encapsulado. A base desta tecnologia é um polímero de celulose presente num reservatório plástico, que propicia alta capacidade de ligação dos alérgenos proteicos relevantes, inclusive aqueles presentes em baixos níveis. Esta fase sólida tem uma altíssima capacidade de ligação, cerca de 150 vezes maior que a de uma superfície inerte de um tubo recoberto. Isso, associado a outras características do ImmunoCAP®, confere alta velocidade do sistema de teste, precisão e reprodutibilidade, o que contribui para as altas sensibilidade e especificidade dos ensaios.

Portanto, o alérgeno a ser estudado é acoplado por ligação covalente ao ImmunoCAP® e reage com as moléculas de $\lg E$ específicas contidas na amostra de soro do paciente. Após a eliminação das IgE não-específicas por lavagem, são adicionados anticorpos lgG anti lgE marcados com uma enzima, de modo a formar um complexo lgE - anti lgE marcado. Após a incubação, os anticorpos anti-IgE-enzima não ligados são eliminados por nova lavagem. $\mathrm{Na}$ última etapa, o complexo ligado é incubado com a solução reveladora (substrato fluorescente para ação da enzima) durante 10 minutos, sendo a reação interrompida pela adição de carbonato de cálcio. Então, a fluorescência do eluato é medida (Bousquet $J$ et al., 1990; Leimgruber et al., 1989; Johansson et al., 1988). Quanto mais elevada é a fluorescência do eluato, maior é a quantidade de $\lg E$ específica presente na amostra.

Os resultados da amostra dos pacientes são comparados diretamente com os resultados obtidos pelos calibradores, que tem a função de avaliar se os resultados liberados estão de acordo com as condições ideais para 0 funcionamento do aparelho (Wide et al., 1967; Johansson et al., 1988; Pastorello et al., 1991).

Esta metodologia tem a capacidade de detectar lgEs séricas específicas $\geq 0,10 \mathrm{KU} / \mathrm{L}$. Porém, neste estudo, para classificação dos grupos citados anteriormente, foram considerados positivos os exames com lgE sérica específica $\geq 0,35 \mathrm{KU} / \mathrm{L}$. 


\subsubsection{Prova de função pulmonar}

As espirometrias foram realizadas utilizando-se um espirômetro Koko, no Ambulatório de Imunologia Clínica e Alergia do HC-FMUSP. Os pacientes foram orientados a não fazer uso de medicações broncodilatadoras de curta duração de 6 a 8 horas antes da realização do exame e o tratamento com broncodilatadores de longa duração foi suspenso durante 12 horas antes do teste.

$\mathrm{Na}$ realização do exame, os pacientes permaneceram sentados em posição vertical, utilizando um clipe nasal. O teste foi considerado adequado quando os pacientes realizavam três manobras consistentes com variação menor de $150 \mathrm{ml}$ entre elas em relação à capacidade vital forçada (CVF) e ao volume expiratório forçado no primeiro segundo $\left(\mathrm{VEF}_{1}\right)$, sendo analisada a melhor curva. Os testes foram repetidos 15 minutos após a inalação de 400 mcg de salbutamol em forma de aerossol dosimetrado.

Os procedimentos técnicos para a realização e a interpretação do exame seguiram as recomendações dos Consensos Internacionais de ATS/ERS (2005). Para a avaliação foi utilizado os valores espirométricos de referência para a população brasileira descritos por Pereira e colaboradores (2002).

\subsubsection{Tipificação HLA classe I e II}

Para a tipificação do HLA foi colhida uma amostra de $10 \mathrm{~mL}$ de sangue periférico em tubo contendo $25 \mathrm{mM}$ de EDTA. As amostras foram encaminhadas para o Laboratório de Imunologia de Transplantes do INCOR. A extração do DNA genômico do sangue periférico de todos os participantes foi realizada utilizando-se o Kit QIAmp® DNA Blood Kit (QIAGEN, Valencia,EUA), de acordo com as instruções do fabricante.

A tipificação dos loci HLA A, B e DR dos doadores falecidos foi realizada pela metodologia PCR-SSP, reação de polimerização em cadeia utilizando sequência específica de primers (do inglês, Polymerase Chain Reaction Sequence Specific Primers) utilizando o kit LABType SSP (One Lambda, California, USA) e seguindo as normas deste fabricante. 
A tipificação HLA A, B, C, DQ, DR e DP dos pacientes com asma, assim como a tipificação do HLA C, DQ e DP dos doadores falecidos, foi realizada utilizando a metodologia PCR-SSO (do inglês, Polymerase Chain Reaction Sequence Specific Olegonucleotide) por meio do kit LABType SSO (One Lambda, INC., Conoga Park, California, USA), de acordo com as orientações do fabricante.

\subsection{Análise estatística}

A frequência dos alelos HLA foi comparada entre os três grupos, utilizando o teste do qui-quadrado de Pearson ou o teste exato de Fisher. O mesmo teste foi utilizado para realizar a comparação de pares de grupos e os valores $p$ foram ajustados pelo método de Holm (Bonferroni sequencial). $V$ de Cramér foi computado como o tamanho do efeito e o intervalo de confiança 95\% bootstrap BCa (DiCiccio e Efron, 1996) com base em 2.000 repetições foi relatado.

Um classificador em árvore de decisão foi utilizado para prever a associação de grupo com base nos alelos HLA utilizando o algoritmo Classification and Regression Trees (CART) (Breiman et al., 1984). A árvore foi podada com base em uma validação cruzada de 10 subamostras para evitar sobreajuste e uma matriz de confusão foi calculada para avaliar a sua qualidade. Uma segunda árvore também foi ajustada com a mesma metodologia excluindo os indivíduos do grupo controle.

Ambos os grupos de asma, alérgica e não alérgica, também foram comparados em algumas variáveis clínicas, utilizando o teste exato de Fisher para as quantidades categóricas e teste $t$ de Student (resíduos normais, caso homoscedástico), teste de Wilcoxon-Mann-Whitney (resíduos não normais, mesmo parâmetro de escala) e o teste Brunner-Munzel (Brunner e Munzel, 2000; resíduos não normais, os parâmetros de escala diferentes) para as variáveis numéricas. V de Cramér e os tamanhos de efeito $d$ de Cohen com seus respectivos intervalos de confiança de 95\% foram calculados. Por fim, a associação de AINES com cada alelo de HLA foi avaliada com o teste qui- 
quadrado de Pearson ou exato de Fisher com o efeito que está sendo medido com razão de chances. Para a associação com lgE, o teste de Wilcoxon-MannWhitney foi utilizado com o tamanho do efeito $d$ de Cohen. Todas as análises foram realizadas no $\mathrm{R} 3.1 .2$ e o nível de significância adotado foi de 5\%. 
4 RESULTADOS 


\subsection{Caracterização dos participantes do estudo}

Cento e noventa pacientes com o diagnóstico de asma de acordo com as diretrizes da GINA em acompanhamento no ambulatório de Asma do Serviço de Imunologia Clínica e Alergia do HC-FMUSP foram entrevistados e convidados a participar do estudo. Oitenta e um (42,63\%) não preencheram os critérios de inclusão: 46 por história de tabagismo, 23 por resultados discrepantes do teste de sensibilização in vivo e in vitro, 1 paciente não aceitou participar da pesquisa, 7 tinham idade superior a 75 anos e 4 por outros motivos. Portanto, foram incluídos no estudo 109 pacientes com diagnóstico de asma confirmada, subdivididos em grupos alérgico $(n=56)$ e não alérgico $(\mathrm{n}=53)$, além de 297 doadores falecidos de órgãos sólidos (grupo controle na análise de tipificação do HLA), totalizando 406 participantes.

A idade média dos participantes e a distribuição dos sexos estão representadas na tabela 3 e os dados referentes à cor da pele na tabela 4 . Não havia dados disponíveis referentes à cor da pele dos indivíduos do grupo controle.

A idade média de início dos sintomas da asma foi de 12,8 anos no fenótipo alérgico e de 25,38 anos no grupo não alérgico $(p<0,001)$. Analisando os antecedentes pessoais de doenças atópicas, observou-se que a rinite estava presente em 41 (73,21\%) e 49 (92,45\%) pacientes com asma alérgica e não alérgica, respectivamente. Entretanto, a dermatite atópica e a conjuntivite alérgica estavam associadas especificamente com a asma alérgica $(p=0,034)$. Não houve diferença estatística entre os grupos na avaliação dos antecedentes familiares de doenças atópicas. A história sugestiva de intolerância aos antiinflamatórios não esteroidais foi mais prevalente na asma não alérgica (60,38\%) do que na alérgica $(17,86 \%)$, conforme observado na Tabela $5(p<0,001)$. 
Todos os pacientes com asma estavam em tratamento medicamentoso. Quando a dose de corticóide inalatório utilizada no tratamento foi analisada, verificou-se que $80,36 \%$ dos pacientes do grupo alérgico e 49,06\% do grupo não alérgico estavam em uso de corticóide inalatório em altas doses segundo critérios da GINA 2012 ( $p<0,001)$. Na avaliação da gravidade da obstrução ao fluxo aéreo pela prova de função pulmonar conforme as Diretrizes Brasileiras (2002), os pacientes do fenótipo alérgico apresentaram maior obstrução brônquica do que os pacientes do fenótipo não alérgico $(p=0,031)($ Tabela 3$)$. 
Tabela 3 - Características dos participantes do estudo

\begin{tabular}{|c|c|c|c|c|c|c|c|c|}
\hline & \multirow[t]{2}{*}{ Asma Alérgica } & \multirow[t]{2}{*}{$\begin{array}{l}\text { Asma não } \\
\text { alérgica }\end{array}$} & \multirow[t]{2}{*}{ Controle } & \multirow[t]{2}{*}{ Valor-p } & \multicolumn{4}{|c|}{ Cramér's V } \\
\hline & & & & & & $\begin{array}{c}\text { Cohen's } \\
\text { d }\end{array}$ & $\begin{array}{l}95 \% \\
\text { Cl.lo }\end{array}$ & $\begin{array}{l}95 \% \\
\text { Cl.hi }\end{array}$ \\
\hline Idade em anos - Média(DP) & $44,14(14,45)$ & $57,09(12,15)$ & $43,03(17,55)$ & $<0.001$ & 1 & & & \\
\hline Sexo feminino $-n^{0}(\%)$ & $44(78,57 \%)$ & $46(86,79 \%)$ & $114(38,38 \%)$ & $<0.001$ & 5 & & & \\
\hline Idade de início dos sintomas em anos - Média(DP) & $12,80(11,82)$ & $25,38(19,79)$ & & $<0.001$ & 4 & 0,777 & 0,383 & 1,170 \\
\hline VEF1 (\%) (DP) & $65,46(14,22)$ & $71,64(15,33)$ & & 0,031 & 2 & 0,418 & 0,035 & 0,801 \\
\hline Contagem de eosinófilos mil/mm³ - Média(DP) & $0,29(0,24)$ & $0,30(0,23)$ & & 0,875 & 3 & 0,024 & $-0,355$ & 0,403 \\
\hline Nível sérico de lgE Ul/mL - Média(DP) & $523,60(819,70)$ & $160,00(352,50)$ & & $<0.001$ & 4 & 0,569 & 0,180 & 0,958 \\
\hline
\end{tabular}

${ }^{1}$ Teste de Kruskal-Wallis; ${ }^{2}$ Teste t de Student; ${ }^{3}$ Teste de Wilcoxon-Mann-Whitney; ${ }^{4}$ Teste de Brunner-Munzel; ${ }^{5}$ Teste qui-quadrado de Pearson 
Tabela 4 - Distribuição de acordo com a cor da pele dos pacientes com asma alérgica e não alérgica

\begin{tabular}{lcc}
\hline Cor da Pele & Asma Alérgica & Asma Não Alérgica \\
& $\mathbf{N}(\%)$ & $\mathbf{N}(\%)$ \\
\hline Branca & $35(62,50)$ & $37(69,81)$ \\
Negra & $9(16,07)$ & $6(11,32)$ \\
Amarela & $0(0)$ & $0(0)$ \\
Parda & $12(21,42)$ & $10(18,86)$ \\
Índio & $0(0)$ & $0(0)$ \\
\hline
\end{tabular}

Dados apresentados como $\mathrm{n}(\%)$

Tabela 5 - Dados dos pacientes dos grupos asma alérgica e não alérgica

\begin{tabular}{|c|c|c|c|c|c|c|c|}
\hline & \multirow{2}{*}{$\begin{array}{c}\text { Asma } \\
\text { Alérgica } \\
\text { N (\%) }\end{array}$} & \multirow{2}{*}{$\begin{array}{c}\text { Asma não } \\
\text { alérgica } \\
\mathbf{N}(\%)\end{array}$} & \multirow[b]{2}{*}{ Valor-p } & \multicolumn{4}{|c|}{ Cramér's V } \\
\hline & & & & & Estimate & 95\%Cl.Io & 95\%Cl.hi \\
\hline Antecedentes pessoais & & & 0,034 & 1 & 0,255 & 0,089 & 0,380 \\
\hline Rinite & $41(73,21)$ & $49(92,45)$ & & & & & \\
\hline Dermatite Atópica & $5(8,93)$ & $1(1,89)$ & & & & & \\
\hline Conjuntivite Alérgica & $10(17,86)$ & $3(5,66)$ & & & & & \\
\hline Antecedentes familiares & & & 0,266 & 1 & 0,193 & 0,035 & 0,314 \\
\hline Asma & $24(42,86)$ & $26(49,06)$ & & & & & \\
\hline Nega & $21(37,50)$ & $14(26,42)$ & & & & & \\
\hline Rinite & $6(10,71)$ & $3(5,66)$ & & & & & \\
\hline Rinite + Asma & $5(8,93)$ & $10(18,87)$ & & & & & \\
\hline \multicolumn{2}{|c|}{ Dose de corticóide inalatório } & & 0,001 & 1 & 0,337 & 0,131 & 0,480 \\
\hline Baixa & $3(5,36)$ & $4(7,55)$ & & & & & \\
\hline Moderada & $8(14,29)$ & $23(43,40)$ & & & & & \\
\hline Alta & $45(80,36)$ & $26(49,06)$ & & & & & \\
\hline AINEs & & & $<0.001$ & 1 & 0,437 & 0,260 & 0,595 \\
\hline Não & $46(82,14)$ & $21(39,62)$ & & & & & \\
\hline Sim & $10(17,86)$ & $32(60,38)$ & & & & & \\
\hline
\end{tabular}

${ }^{1}$ Teste exato de Fisher 
O teste cutâneo de puntura e a pesquisa da $\lg E$ sérica específica para os aeroalérgenos selecionados foram realizados em todos os participantes com asma. A sensibilização dos pacientes do fenótipo alérgico está demonstrada nas figuras 3 e 4 . Somente cinco pacientes eram monossensibilizados segundo o teste cutâneo, sendo três para Dermatophagoides pteronyssinus e dois para Blomia tropicalis.

A média dos níveis séricos da lgE total nos pacientes com asma foi de 523,60 Ul/mL no grupo alérgico e de $160 \mathrm{UI} / \mathrm{mL}$ no fenótipo não alérgico $(p<0,001)$. A média da contagem sanguínea dos eosinófilos foi similar nos dois grupos de asma (Tabela 3).

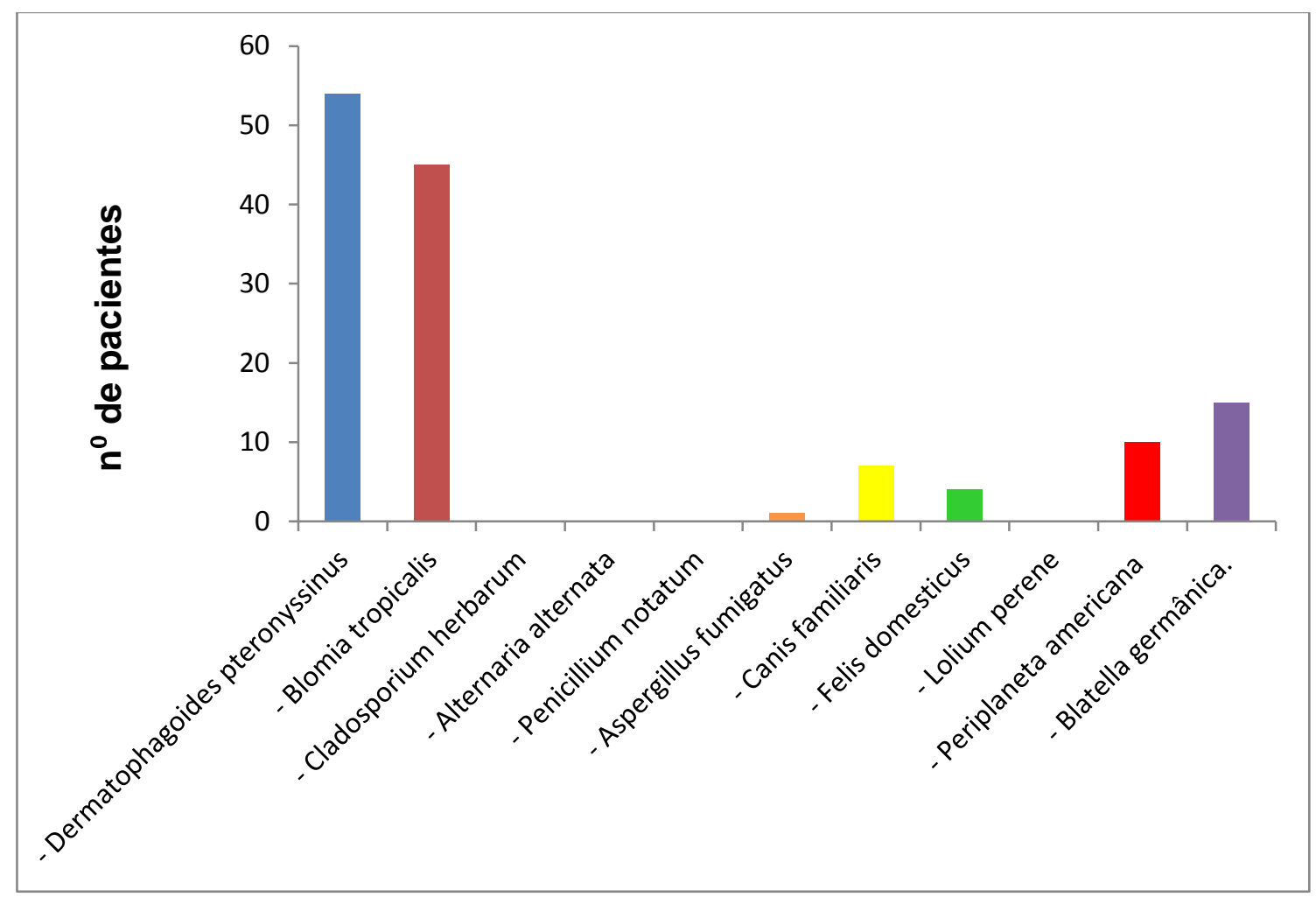

Figura 3 - Resultado do teste cutâneo de puntura nos pacientes com asma alérgica 


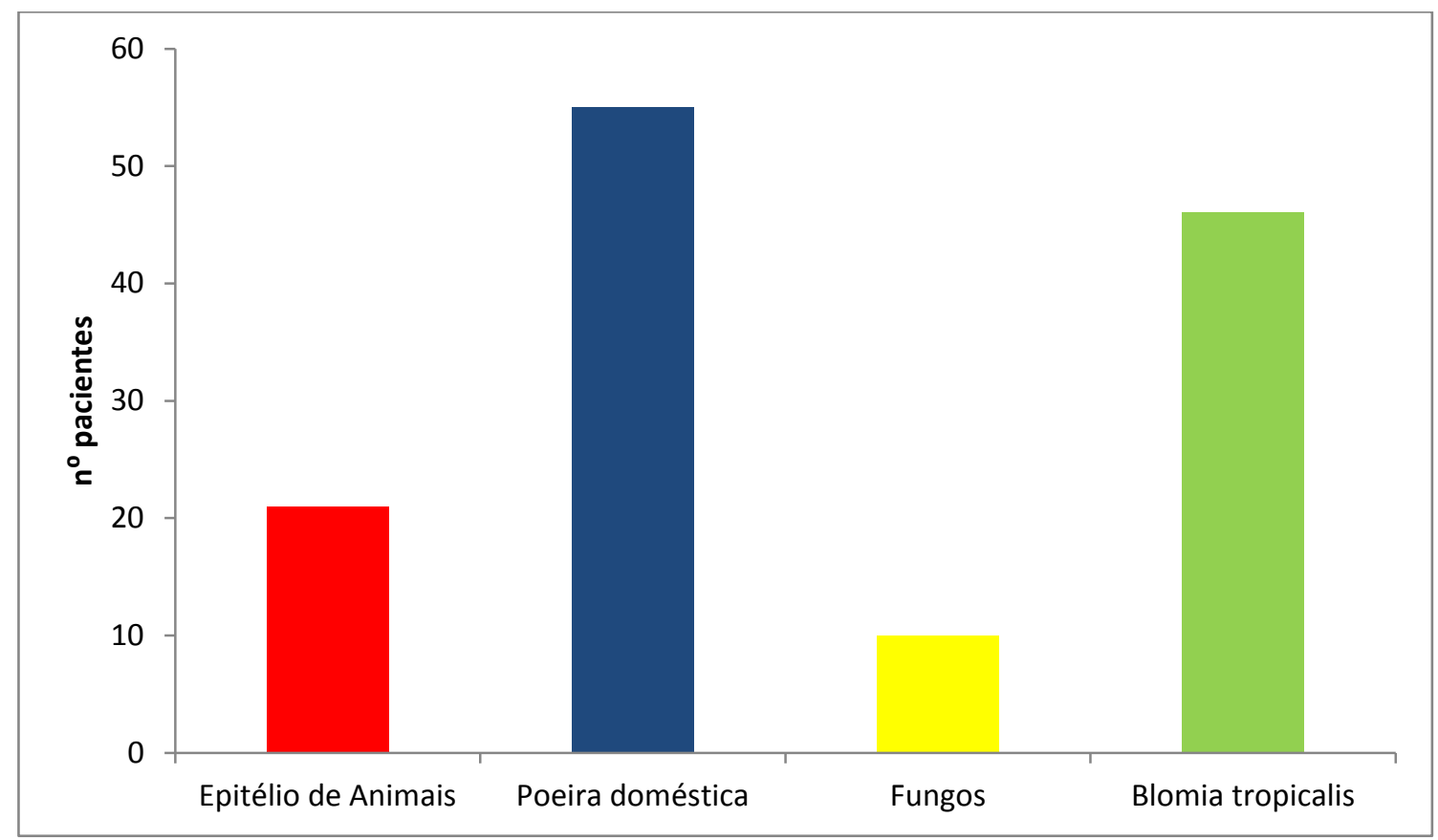

Figura 4 - Resultado da pesquisa de IgE sérica específica nos pacientes com asma alérgica

\subsection{Tipificação dos alelos HLA}

A tipificação do HLA para classe I (A, B e C) e classe II (DQ, DR e DP) foi realizada em todos os participantes, com exceção de um doador falecido de órgão sólido cujo material genético armazenado não permitiu a análise para o HLA locus C. As frequências dos alelos HLA observadas estão demonstradas nos anexos 3,4,5,6,7 e 8 .

Na comparação dos três grupos envolvidos no estudo, houve associação dos alelos HLA-B*42 ( $p=0,040), H^{*} A-C^{*} 17(p=0,040), H_{L A}-D P A 1 * 03(p=0,013)$ e HLA-DPB1*105 ( $p=0,036)$ com o grupo asma alérgica. Por outro lado, o alelo HLA-B*48 $(p=0,031)$ estava mais presente nos pacientes do fenótipo não alérgico (Tabela 6).

$\mathrm{Na}$ comparação isolada dos grupos asma alérgica e controle, houve associação dos alelos HLA-DPA1*03 e HLA-DPB1*105 com o fenótipo alérgico. $\mathrm{Na}$ análise dos alelos HLA classe I e II no grupo não alérgico versus controle 
não se observaram associações estatisticamente significantes. A frequência do HLA-A*02 nos fenótipos alérgico e não alérgico da asma foi 30,36\% e 52,83\%, respectivamente, e a diferença apresentou valor de $p$ limítrofe $(p=0,052)$.

$\mathrm{Na}$ análise do HLA dos três grupos participantes do estudo através da árvore de decisão, verificou-se que a presença da associação HLA-DQA1*05 DPA1*03 está associada com a asma alérgica. O fenótipo não alérgico apresentou associação com a presença do HLA-DPA1*03 e a ausência do HLA-DQA1*05 (Figura 5). A ausência do alelo HLA-DPA1*03 prevaleceu no grupo controle. Nesta análise os valores preditivos positivo para asma alérgica, não alérgica e grupo controle foram 62,5\%, 42,9\% e 74,9\%, respectivamente.

A árvore de decisão analisando apenas os grupos asma alérgica e não alérgica mostrou que a presença simultânea dos alelos HLA-*02 e HLA-C*05, assim como a ausência do HLA-A*02 e do HLA-B*08 estão associadas com a asma alérgica. Por outro lado, a ausência do alelo $H L A-A^{\star} 02$ e presença do HLA-B*08, assim como a presença do HLA-A*02 e ausência do HLA-C*05 estiveram associadas ao fenótipo asma não alérgica (Figura 6). Estas associações apresentam sensibilidade de 78,6\% e 62,3\% e especificidade de 62,3\% e $78,6 \%$ para os fenótipos alérgico e não alérgico, respectivamente. 
Tabela 6 - Frequência dos antígenos HLA classe I e II e comparação entre os grupos

\begin{tabular}{|c|c|c|c|c|c|c|c|c|c|c|c|}
\hline & $\begin{array}{l}\text { Asma } \\
\text { Alérgica } \\
\text { N (\%) }\end{array}$ & $\begin{array}{c}\text { Asma não } \\
\text { alérgica } \\
\text { N (\%) }\end{array}$ & $\begin{array}{l}\text { Controle } \\
\text { N (\%) }\end{array}$ & Valor-p & & $\begin{array}{l}\text { Asma alérgica } \\
\text { x Asma não } \\
\text { alérgica }\end{array}$ & $\begin{array}{c}\text { Asma alérgica } \\
\text { x Controle }\end{array}$ & $\begin{array}{l}\text { Asma não } \\
\text { alérgica x } \\
\text { Controle }\end{array}$ & Estimate & $\begin{array}{l}\text { Cramér's V } \\
95 \% \mathrm{Cl} .10\end{array}$ & 95\%Cl.hi \\
\hline$A * 02$ & $17(30,36)$ & $28(52,83)$ & $116(39,06)$ & 0,052 & 1 & 0,052 & 0,218 & 0,121 & 0,104 & 0,060 & 0,142 \\
\hline$B * 42$ & $4(7,14)$ & $2(3,77)$ & $5(1,68)$ & 0,040 & 2 & 0,679 & 0,116 & 0,574 & 0,117 & 0,018 & 0,229 \\
\hline$B * 48$ & $0(0)$ & $3(5,66)$ & $2(0,67)$ & 0,031 & 2 & 0,223 & 1,000 & 0,079 & 0,157 & 0,046 & 0,310 \\
\hline$C * 17$ & $6(10,71)$ & $3(5,66)$ & $10(3,38)$ & 0,040 & 2 & 0,854 & 0,083 & 0,854 & 0,120 & 0,022 & 0,237 \\
\hline DPA $1 * 03$ & $7(12,50)$ & $4(7,55)$ & $4(2,56)$ & 0,013 & 2 & 0,391 & 0,026 & 0,229 & 0,159 & 0,073 & 0,226 \\
\hline DPB1*105 & $7(12,50)$ & $3(5,66)$ & $5(3,21)$ & 0,036 & 2 & 0,644 & 0,049 & 0,644 & 0,159 & 0,035 & 0,285 \\
\hline
\end{tabular}

${ }^{1}$ Teste qui-quadrado de Pearson; ${ }^{2}$ Teste exato de Fisher; Post hoc corrigido pelo método de Holm (Bonferroni sequencial) 


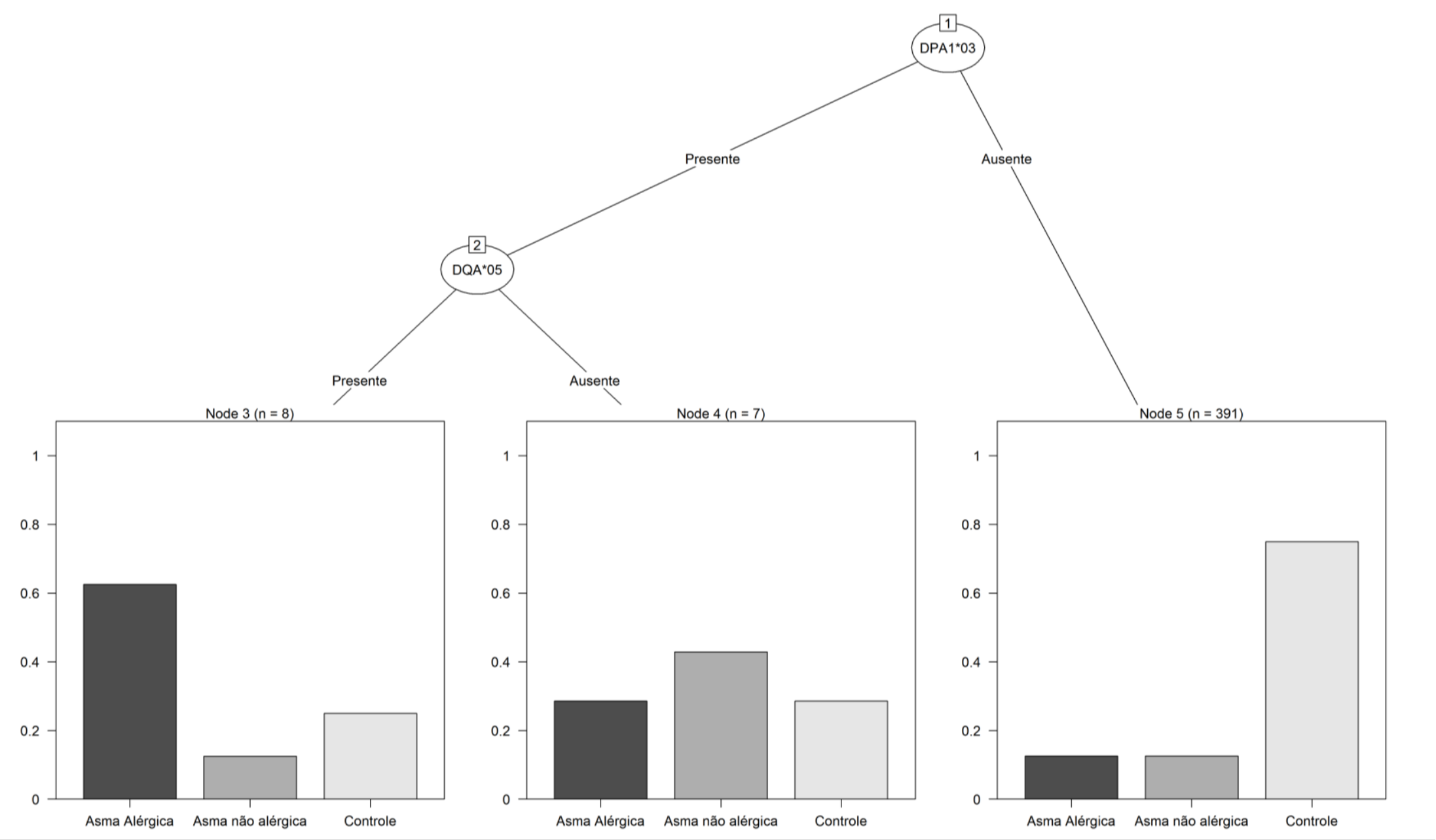

Figura 5 - Análise por árvore de decisão do HLA dos três grupos participantes 


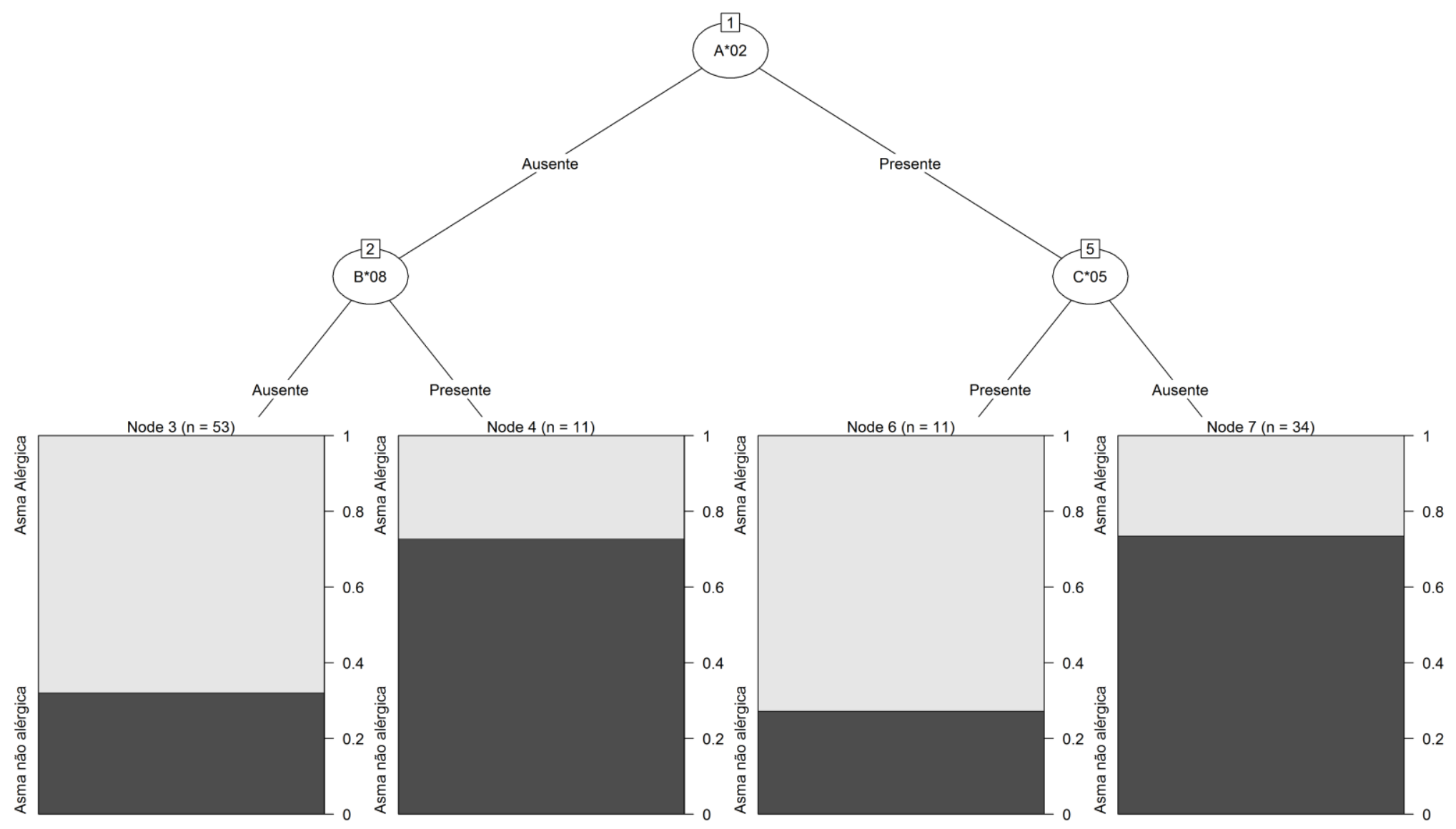

Figura 6 - Análise por árvore de decisão dos grupos asma alérgica e não alérgica 
Os pacientes com asma com história sugestiva de intolerância aos AINES tinham os alelos HLA-B*40 e HLA-DRB1*04 com maior frequência e os alelos HLA-A*68, HLA-B*58 e HLA-DRB1*13 com menor frequência do que os pacientes tolerantes aos AINES (Tabela 7). A presença dos alelos HLA-A*30 e HLA-C*17 e ausência dos alelos HLA-A*02, HLA-B*38, HLA-B*44, HLA-DRB1*16 e HLA-DQB1*03 estavam correlacionados com níveis séricos de lgE maiores, conforme tabela 8.

Tabela 7 - Análise dos pacientes com asma com e sem história sugestiva de hipersensibilidade a AINES

\begin{tabular}{|c|c|c|c|c|c|c|c|}
\hline \multirow[t]{3}{*}{ HLA } & \multicolumn{2}{|c|}{ AINES } & \multirow[b]{3}{*}{ Valor-p } & & \multirow[b]{3}{*}{ OR } & \multirow[b]{3}{*}{ 95\%Cl.lo } & \multirow[b]{3}{*}{ 95\%Cl.hi } \\
\hline & Não & Sim & & & & & \\
\hline & N (\%) & N (\%) & & & & & \\
\hline$A * 68$ & $12(17,9)$ & $2(4,8)$ & 0,046 & 1 & 0,23 & 0,02 & 1,13 \\
\hline$B * 40$ & $2(3,0)$ & $7(16,7)$ & 0,026 & 2 & 6,39 & 1,14 & 66,32 \\
\hline$B * 58$ & $7(10,4)$ & $0(0)$ & 0,042 & 2 & & & \\
\hline DRB1*04 & $9(13,4)$ & $13(31,0)$ & 0,027 & 1 & 2,86 & 1,00 & 8,56 \\
\hline DRB1*13 & $26(38,8)$ & $7(16,7)$ & 0,014 & 1 & 0,32 & 0,10 & 0,87 \\
\hline
\end{tabular}

${ }^{1}$ Teste qui-quadrado de Pearson; ${ }^{2}$ Teste exato de Fisher 
Tabela 8 - Média dos níveis séricos de IgE e associação com HLA classe I e II

\begin{tabular}{lcccccccc}
\hline HLA & HLA Ausente & \multicolumn{2}{c}{ HLA Presente } & & & \\
N & IgE Média (DP) & N & IgE Média (DP) & Valor-p & Cohen's d & 95\%Cl.lo & 95\%Cl.hi \\
\hline$A^{*} 02$ & 63 & $492,38(825,18)$ & 45 & $147,19(185,39)$ & $<0.001$ & 0,537 & 0,144 & 0,930 \\
\hline$A^{*} 30$ & 95 & $305,88(531,46)$ & 13 & $660,38(1253,98)$ & 0,036 & 0,542 & $-0,048$ & 1,131 \\
\hline$B^{*} 38$ & 106 & $354,89(666,38)$ & 2 & $12,50(4,95)$ & 0,036 & 0,516 & $-0,898$ & 1,930 \\
\hline$B^{*} 44$ & 83 & $393,85(732,82)$ & 25 & $198,16(294,78)$ & 0,031 & 0,297 & $-0,156$ & 0,750 \\
\hline$C^{*} 17$ & 99 & $348,32(689,47)$ & 9 & $351,11(184,25)$ & 0,029 & 0,004 & $-0,685$ & 0,693 \\
\hline DRB1*16 & 103 & $362,78(674,44)$ & 5 & $55,40(50,23)$ & 0,039 & 0,465 & $-0,444$ & 1,373 \\
\hline DQB1 ${ }^{*} 03$ & 51 & $406,94(738,32)$ & 57 & $296,31(586,63)$ & 0,029 & 0,167 & $-0,215$ & 0,549 \\
\hline
\end{tabular}

Teste de Wilcoxon-Mann-Whitney 
5 DISCUSSÃO 
A asma é uma das doenças crônicas mais prevalentes no mundo, podendo apresentar alta morbidade, principalmente se não for tratada adequadamente, e inclusive ser fatal. Além de prevalente, a asma é uma doença heterogênea e a identificação de seus fenótipos e subfenótipos permite melhor compreensão da sua fisiopatologia, resposta terapêutica e prognóstico (Giavina-Bianchi et al., 2013; Giavina-Bianchi , 2015). A identificação de uma provável associação do sistema HLA com os fenótipos alérgico e não alérgico da asma é importante para a elucidação de sua fisiopatologia, em particular da doença não alérgica.

No presente estudo observou-se que a média da idade de início dos sintomas da asma nos dois fenótipos estudados foi estatisticamente diferente, sendo mais precoce na asma alérgica e mais tardia nos pacientes não alérgicos, resultado compatível com a literatura. A asma é mais comum em indivíduos do sexo masculino na infância, tornando-se mais prevalente e mais grave nas mulheres após a adolescência (Jenkins et al., 2003; Dolan et al., 2004). Observamos a prevalência do sexo feminino de $78,57 \%$ nos pacientes com asma alérgica e de $86,79 \%$ no grupo com asma não alérgica.

Estudos demonstraram que 5 a $20 \%$ dos pacientes com asma, principalmente os que apresentam o fenótipo não alérgico da doença, têm intolerância aos anti-inflamatórios não esteroidais. Esta prevalência pode chegar a $40 \%$ nos pacientes com a Síndrome de Samter caracterizada pela intolerância à aspirina, asma brônquica e rinossinusite crônica com pólipos nasais. (Menz et al., 1998; Specjalski et al.,2006; Comert et al., 2013). O presente estudo confirma estes dados, os pacientes com asma não alérgica apresentando maior prevalência de intolerância aos anti-inflamatórios não esteroidais do que os pacientes com asma alérgica. Entretanto, as reações adversas a este grupo de medicamentos também são relevantes no fenótipo alérgico.

A asma de fenótipo não alérgico é caracterizada por uma maior gravidade da doença (Rackeman, 1947; ENFUMOSA, 2003). Entretanto, 
nossos pacientes com asma alérgica apresentaram obstrução brônquica mais grave, conforme observado nos testes de função pulmonar, e maior dose de corticóide inalatório utilizada do que os pacientes não alérgicos.

A IgE é um anticorpo produzido em resposta à exposição alergênica, embora níveis elevados também possam ser encontrados em outras afecções, como Síndrome Hiper lgE, aspergilose broncopulmonar alérgica, nefrite intersticial por drogas e parasitoses intestinais (Daher et al., 2009). O fato do Brasil ser um país endêmico em parasitose intestinal limita a utilização da eosinofilia e da lgE sérica total como marcadores na asma. Como era esperado, observamos níveis séricos de IgE maiores na asma alérgica e a contagem dos eosinófilos sanguíneos foi similar nos dois fenótipos da doença.

Antecedentes pessoais e familiares de doenças atópicas são característicos da asma alérgica. A presença de rinite não diferenciou os fenótipos da asma em nossos pacientes, inclusive sendo mais prevalente no fenótipo não alérgico. Entretanto, a presença de dermatite atópica e conjuntivite alérgica estiveram associadas com a asma alérgica $(p=0,034)$. Não foi observada diferença estatisticamente significativa quanto à história familiar de atopia.

$\mathrm{Na}$ literatura, os estudos correlacionando asma e o sistema HLA classe I e II são inconsistentes conferindo aumento do risco ou proteção para a doença. O pequeno número amostral, não considerar a asma uma doença com diferentes fenótipos, diversidade dos alelos HLA classe I e II selecionados no estudo, existência de alelos desconhecidos, características étnicas populacionais e metodologia aplicada na tipificação do HLA são limitações destes estudos.

$\mathrm{Na}$ literatura, os trabalhos envolvendo HLA classe I e asma apresentam diferentes resultados dependendo da população estudada. Apostolakis et at. (1996) avaliaram a possível associação entre HLA e a idade de início dos sintomas da asma. Foi observada maior frequência do alelo HLA-A10 e menor do HLA-B5 em pacientes com início da doença até 17 anos de idade, assim como maior freqüência do alelo HLA-B8 nos pacientes com início mais tardio. Por outro lado, em estudo com crianças da Croácia, o HLA-B8 foi associado com níveis de IgE elevados e o fenótipo alérgico da doença (Ikovic Jurekovic et al., 2011).

Morris et al. (1977) relataram em uma população caucasiana aumento não significativo da frequência do HLA-A1 e HLA-B8 na asma alérgica e 
frequência menor não significativa do HLA-B12 em pacientes com asma não alérgica. Posteriormente, o mesmo grupo de pesquisadores observou um aumento da frequência de HLA-B12 em pacientes com asma alérgica e menor frequência dos alelos HLA-A3, HLA-B7 e HLA-DR2 no fenótipo não alérgico (Morris et al., 1980). Outro estudo realizado com crianças indianas não observou associação entre asma e HLA classe I (Mishra et al., 2014).

O HLA-DQ foi o primeiro locus descrito que mostrou a associação com a asma. (Marsh et al., 1981). O estudo GABRIEL consortium envolveu uma amostra de 10365 participantes com asma e 16110 controles e identificou associação da região do HLA-DQ com o início tardio (16 anos ou mais) da doença (Moffat et al., 2010). O estudo TENOR relatou a associação da região RAD50-II13 e do HLA-DR/DQ com suscetibilidade para asma em pacientes com asma grave ou de difícil controle ( $\mathrm{Li} X$ et al.,2010). Outro estudo na população da Venezuela sugeriu que o haplótipo HLA-DRB1*1101 HLA-DQA1*0501 HLA-DQB1*0301 está associado com a asma alérgica, conferindo suscetibilidade para a doença induzida pelo ácaro Dermatophagoides spp. Também concluíram que o HLA-C7 teria um papel protetor para o desenvolvimento do fenótipo alérgico (LaraMarquez et al., 1999). Gao et al. (2003) observaram que o alelo HLA-DQA1*0104 e o HLA-DQB1 *0201 conferem suscetibilidade; e o HLA-DQA1*0301 e o HLA-DQB1*0301 protegem contra o desenvolvimento da asma alérgica.

Muitos estudos têm relatado a associação entre diferentes alelos envolvendo o HLA-DQ e HLA-DR e a asma alérgica induzida por alérgenos específicos. O haplótipo HLA-DRB ${ }^{*} 01$ DQB $1{ }^{*} 0501$ foi associado à sensibilização por Artemisia vulgaris em população da Espanha (Torio et al., 2003). Um estudo em crianças norueguesas mostrou associação do haplótipo HLA-DQB1*0603 DRB1*13 com sensibilização à bétula e do haplótipo HLA-DQB1*0609 DRB1*13 e HLA-DQB1*0501 DRB1*01 com Artemisia vulgaris (Munthe-kaas et al.,2007). Em relação à sensibilização por fungos, Knutsen et al. (2010) observaram que 0 antígeno $\mathrm{HLA}-\mathrm{DQB} 1{ }^{*} 03$ está presente numa frequência menor em crianças com asma grave sensibilizadas a Alternaria, sugerindo um fator protetor do alelo para a doença.

$\mathrm{Na}$ literatura existem poucos trabalhos que avaliaram a associação entre asma e alelos HLA-DP. O primeiro GWAS na população asiática identificou a presença do HLA-DPA1*0201 e do HLA-DPB1*0901 em crianças com asma 
(Noguchi et al., 2011). Caraballo et al. (1991) observaram em pacientes mulatos com asma alérgica frequência estatisticamente menor do alelo HLA-DPB1*0401, sugerindo que a presença do alelo teria um caráter protetor para o desenvolvimento da doença.

No presente estudo, na análise do HLA classe I, os alelos HLA-B*42 e HLA-C*17 apresentaram associação com o fenótipo asma alérgica e o HLA-B*48 com a asma não alérgica. Observamos na análise através da árvore de decisão a associação do fenótipo alérgico com a presença da associação do HLA-A*02 e do HLA-C*05 e a ausência do HLA-A*02 e HLA-B*08. Por outro lado, a asma não alérgica esteve associada à presença do $H L A-A^{*} 02$ e a ausência do HLA-C*05, assim como à ausência do antígeno HLA-A*02 e presença do $\mathrm{HLA}^{*} \mathrm{~B}^{\star} 08$.

$\mathrm{Na}$ análise dos antígenos HLA classe II verificamos que a frequência do alelo HLA-DPA1*03 e do HLA-DPB1*105 foi maior nos pacientes com asma alérgica. Enquanto através da árvore de decisão observamos que a presença da associação do HLA-DPA ${ }^{*} 03$ e do HLA-DQA ${ }^{*} 05$ foi associada com a asma alérgica; e a presença do HLA-DPA ${ }^{*} 03$ e a ausência do alelo HLA-DQA ${ }^{*} 05$ com o fenótipo não alérgico.

Estudo semelhante ao nosso analisou a frequência do HLA classe I e II em pacientes com asma alérgica e não alérgica, porém não incluindo a tipificação do locus HLA-DP. Observou maior frequência dos alelos HLA-A1, HLA-B7 e HLA-DQB1* 0302 e menor do HLA-B18 nos pacientes com asma não alérgica, mas estas diferenças não foram estatisticamente significantes (Torio et al., 2000).

Em relação à associação asma e reações de hipersensibilidade aos antiinflamatórios não esteroidais, estudos realizados em diferentes populações, caucasianas e asiáticas, mostraram o HLA-DPB1*0301 como um fator de risco (Dekker et al., 1997; Choi et al., 2004). Polimorfismo do HLA-DR também foi relacionado com o desenvolvimento de pólipos nasais em pacientes com asma (Kim et al., 2012), observação não confirmada por Jones et al. (1984). Nosso estudo identificou os alelos HLA-A*68, HLA-B*58 e HLA-DRB1*13 como fator protetor e os alelos HLA-B*40 e HLA-DRB1*04 como fator de risco para 0 desenvolvimento de reação de hipersensibilidade aos anti-inflamatórios não esteroidais em pacientes com asma. 
A população brasileira originou-se a partir da miscigenação ocorrida entre caucasianos europeus, índios nativos e negros africanos (Moraes et al.,1993). A análise do polimorfismo do sistema HLA em populações miscigenadas pode revelar diferentes frequências de alelos e haplótipos de HLA em comparação com outros grupos raciais e étnicos, o que pode influenciar nas associações entre HLA e doença. Assim, a tipificação do HLA e identificação de associações com doenças em diferentes populações humanas são de grande valor.

$\mathrm{O}$ presente estudo mostrou que diferentes alelos HLA classe I e II, incluindo alelos HLA-DP, estão associados com os fenótipos alérgico e não alérgico da asma brônquica. Este estudo é inovador e relevante por dois atributos principais. Primeiro por utilizar critérios rigorosos na identificação e comparação dos fenótipos alérgico e não alérgico da asma. Segundo por identificar associações entre HLA e asma não descritas previamente.

Provavelmente existem diversos alelos/haplótipos envolvidos na asma, dependendo do fenótipo da doença e das características étnicas da população estudada. A predisposição genética da asma é poligênica e novos estudos em grandes populações são necessários para confirmar as associações do sistema HLA como fator protetor ou de risco para a doença. 
6 CONCLUSÕES 
O presente estudo identificou a associação entre novos alelos HLA classe I e II e asma alérgica e não alérgica na população brasileira. Os alelos HLA-B*42, HLA-C*17, HLA-DPA1*03 e HLA-DPB1*105 estiveram associados com a asma alérgica e o alelo HLA-B*48 com o fenótipo não alérgico.

A presença da associação do $\operatorname{HLA}-\mathrm{DQA} 1{ }^{*} 05$ e do $\operatorname{HLA}-\mathrm{DPA} 1{ }^{*} 03$ apresentou associação com a asma alérgica; e a presença do HLA-DPA1*03 e ausência do alelo HLA-DQA1*05 com a asma não alérgica.

$\mathrm{Na}$ caracterização dos pacientes com asma alérgica e não alérgica foram observadas características semelhantes às descritas na literatura como idade de início dos sintomas da asma, história sugestiva de intolerância aos anti-inflamatórios não esteroidais, nível sérico da imunoglobulina $E$, história pessoal de dermatite atópica e rinoconjuntivite. Além disso, o sexo feminino foi o mais prevalente nos dois fenótipos da asma estudados. Entretanto, a asma alérgica apresentou maior gravidade do que a não alérgica. 


\title{
Anexo 1
}

HOSPITAL DAS CLÍNICAS DA FACULDADE DE MEDICINA DA UNIVERSIDADE DE SÃO PAULO-HCFMUSP

\author{
MODELO DE TERMO DE CONSENTIMENTO LIVRE E ESCLARECIDO
}

\section{I- DADOS DE IDENTIFICAÇÃO DO SUJEITO DA PESQUISA OU RESPONSÁVEL LEGAL}

1. NOME: .

DOCUMENTO DE IDENTIDADE N ${ }^{\circ}$.

DATA NASCIMENTO: ........................

ENDERECO

BAIRRO:

CEP: TELEFONE: DDD SEXO :.$M \square F \square$

2.RESPONSÁVEL LEGAL

NATUREZA (grau de parentesco, tutor, curador etc.)

DOCUMENTO DE IDENTIDADE : DATA NASCIMENTO: .......................

ENDEREÇO

BAIRRO:

CEP: TELEFONE: DDD (..................

APTO: № № APTO:

\section{II- DADOS SOBRE A PESQUISA}

1. TÍTULO DO PROTOCOLO DE PESQUISA :

Tipificação do MHC nos fenótipos alérgico e não alérgico da asma bronquica 2. PESQUISADOR : Priscila Megumi Takejima CARGO/ FUNÇÃO: Pósgraduanda a nível de Mestrado da Disciplina de Imunologia Clínica e Alergia da Universidade de São Paulo Currículo lattes: http://attes.cnpq.br/2785749806908094 INSCRIÇÃO CONSELHO REGIONAL DE MEDICINA: 116592

UNIDADE DO HC- FMUSP: Serviço de Imunologia Clínica e Alergia do Hospital das Clínicas da Universidade de São Paulo.

PESQUISADOR/ ORIENTADOR: Prof. Dr. Pedro Francisco Giavina-Bianchi Júnior CARGO/FUNÇÃO: Professor Livre Docente e Médico Assistente do Serviço de Imunologia Clínica e Alergia do Hospital das Clínicas da Faculdade de Medicina da Universidade de São Paulo e Professor Colaborador da Disciplina de Imunologia Clínica e Alergia da Faculdade de Medicina da Universidade de São Paulo.

Currículo lattes: http://lattes.cnpq.br/3977658608500572

INSCRIÇÃO CONSELHO REGIONAL MEDICINA № 70.584

UNIDADE DO HC-FMUSP: Serviço de Imunologia Clínica e Alergia do Hospital das

Clínicas da Universidade de São Paulo.

3. AVALIACCÃO DO RISCO DA PESQUISA:

$\begin{array}{ll}\text { RISCO MÍNIMO } & \text { RISCO MÉDIO X } \\ \text { RISCO BAIXO } & \text { RISCO MAIOR }\end{array}$

4. DURAÇÃO DA PESQUISA: 24 meses 


\section{REGISTRO DE EXPLICAÇÕES DO PESQUISADOR AO PACIENTE OU REPRESENTANTE LEGAL SOBRE A PESQUISA, CONSIGNADO:}

1 -Justificativa e objetivo(s)

A asma é uma doença de alta frequência e um problema de saúde pública. A asma é uma doença multifatorial e a influência dos fatores genéticos não é bem conhecida.

O senhor que tem asma está convidado a participar do presente estudo que visa avaliar se um determinado fator genético, o antígeno leucocitário humano, ou HLA, que controla a resposta imunológica (de defesa) e também é capaz de reconhecer substâncias que são estranhas ao organismo, tem algum papel no desenvolvimento ou não da asma.

2- Procedimentos que serão realizados, com seus propósitos e identificação dos que forem experimentais e não rotineiros

Caso o senhor (a) aceite em participar do nosso estudo, o senhor (a) irá responder a um questionário para avaliação da asma e realizará alguns exames:

a) Teste Cutâneo: para identificar se o senhor possui asma do tipo alérgica e quais substâncias podem estar envolvidas com o desencadeamento de sua doença.

b) Coleta de sangue: o senhor precisará retirar sangue para avaliar a produção de anticorpos que causam alergia e para estudarmos seu HLA,

3- Relação dos procedimentos rotineiros e como são realizados

Serão coletadas duas amostras de $10 \mathrm{ml}$ do seu sangue na veia da parte interna do seu braço: uma para a dosagem no laboratório do anticorpo associado ao processo alérgico ( $\mathrm{lg} \mathrm{E})$ e outra para isolar as células do sangue. Além disso, com o objetivo de avaliarmos o seu grau de alergia, realizaremos testes na sua pele do antebraço injetando com uma pequena lanceta pequenas gotas das substâncias mais comuns dos processos alérgicos em oito pontos diferentes (teste cutâneo). Após 8 a 10 minutos a reação será lida medindo-se com uma régua o tamanho de cada ponto.

4- Descrição dos desconfortos e riscos esperados nos procedimentos dos itens 2 e 3.

O teste de alergia na pele poderá desencadear leve desconforto e coceira no local, que geralmente é passageira. Na coleta de sangue poderá haver desconforto do furo da agulha, e, em alguns casos, pode ocorrer inchaço ou dor no local da picada

5- Benefícios para o participante

O melhor conhecimento das causas da asma pode levar a novos tratamentos mais apropriados para cada tipo de asma.

6- Procedimentos alternativos que possam ser vantajosos para o individuo:

Não há procedimentos alternativos.

\section{IV-ESCLARECIMENTOS DADOS PELO PESQUISADOR SOBRE GARANTIAS DO SUJEITO DA PESQUISA CONSIGNANDO:}

Nesta pesquisa o senhor (a):

Serão dadas a qualquer tempo, informações sobre todo os procedimentos, riscos e benefícios relacionados à pesquisa, inclusive para esclarecer quaisquer dúvidas.

Em caso de dúvida ou informações sobre a pesquisa, favor entrar em contato com Priscila Megumi Takejima pelo telefone 30696098. 
Se você tiver alguma consideração ou dúvida sobre a ética da pesquisa, entre em contato com o Comitê de Ética em Pesquisa (CEP) - Rua Ovídio Pires de Campos, 225 - 5o andar - tel: 3069-6442 ramais 16, 17, 18 ou 20, FAX: 3069-6442 ramal 26 E-mail: cappesq@hcnet.usp.br

1. O paciente poderá retirar seu consentimento sobre a pesquisa a qualquer momento e deixar de participar do estudo, sem que isto lhe traga qualquer prejuízo. Ou seja, caso o senhor não queira continuar participando do estudo, terá total liberdade de desistir do mesmo a qualquer momento, sem prejuízo do seu acompanhamento médico.

2. Haverá direito de confidencialidade, sigilo e privacidade sobre as informações e resultados do exame. Seus dados pessoais e resultados de exames serão guardados em segredo, deixando sua privacidade segura.

3. Haverá assistência no HC- FMUSP, por eventuais danos á saúde, devidos a pesquisa, sendo garantidos cuidados médicos no serviço de Imunologia Clínica e Alergia , caso ocorram problemas de saúde decorrentes da pesquisa.

4. Direito de ser mantido atualizado sobre os resultados parciais das pesquisas, quando em estudos abertos, ou de resultados que sejam do conhecimento dos pesquisadores.

5. Não há despesas pessoais para o participante em qualquer fase do estudo, incluindo exames e consultas. Também não há compensação financeira relacionada à sua participação. Se existir qualquer despesa adicional, ela será absorvida pelo orçamento da pesquisa.

\title{
V- INFORMAÇÕES DE NOMES, ENDEREÇOS E TELEFONES DOS RESPOSÁVEIS PELO ACOMPANHAMENTO DA PESQUISA, PARA CONTATO EM CASO DE INTECORRENCIAS CLINICAS E REAÇÕES ADVERSAS.
}

\author{
A principal investigadora é Dra. Priscila Megumi Takejima \\ Contato: Hospital das Clínicas Av. Dr. Enéas de Carvalho Aguiar, 155, $8^{\circ}$ andar. \\ Prédio dos Ambulatórios - Secretaria de Imunologia e Alergia. Telefones: 3069-6098 / \\ 3069-6225 \\ O orientador é Prof. Dr. Pedro Francisco Giavina-Bianchi Júnior Contato: Hospital das \\ Clínicas Av. Dr. Enéas de Carvalho Aguiar, 155, $8^{\circ}$ andar. Prédio dos Ambulatórios - \\ Secretaria de Imunologia e Alergia. Telefones: 3069-6098 / 3069-6225
}

\section{VI.- CONSENTIMENTO PÓS - ESCLARECIDO}

Acredito ter sido suficientemente informado a respeito das informações que li ou que foram lidas para mim, descrevendo o estudo "Tipificação do MHC nos diferentes fenótipos alérgico e não alérgico da asma bronquica"

Eu discuti com a Dra. Priscila Megumi Takejima e Dr. Pedro Francisco Giavina Bianchi Júnior sobre a minha decisão em participar desse estudo. Ficaram claros para mim quais são os propósitos do estudo, os procedimentos a serem realizados, seus desconfortos e riscos, as garantias de confidencialidade e de esclarecimentos permanentes. Ficou claro também que minha participação é isenta de despesas. Concordo voluntariamente em participar deste estudo e poderei retirar o meu consentimento a qualquer momento, antes ou durante o mesmo, sem penalidades ou prejuízo ou perda de qualquer benefício que eu possa ter adquirido, ou no meu atendimento neste Serviço. 
Assinatura do paciente

Data

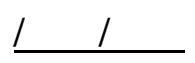

Assinatura do representante legal

Data

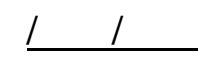

Assinatura da testemunha

Data

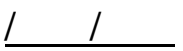

Para casos de pacientes menores de 18 anos, analfabetos, semi-analfabetos ou portadores de deficiência auditiva ou visual.

Somente para o responsável do projeto

(Declaro que obtive de forma apropriada e voluntária o Consentimento Livre e Esclarecido deste paciente ou representante legal para a participação neste estudo.

Dra. Priscila Megumi Takejima

Data

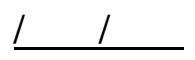

Prof. Dr. Pedro Francisco Giavina-Bianchi Júnior

Data

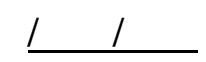




\section{Anexo 2}

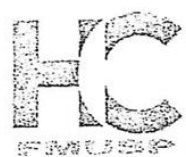

\section{Hospital das Clínicas da FMUSP \\ Comissão de Ética para Análise de Projetos de Pesquisa \\ CAPPesq}

No Protocolo: $0774 / 10$

Título: "TIPIFICAÇÃO DO MHC NOS FENÓTIPOS ALÉRGICO E NÃO ALÉRGICO DA ASMA BRÔNQUICA"

Pesquisador Responsável: Pedro Giavina-Bianchi

Pesquisador Executante: Priscila Megumi Takejima

Departamento: Clínica Médica

A Comissão de Ética para Análise de Projetos de Pesquisa CAPPesq da Diretoria Clínica do Hospital das Clínicas da Faculdade de Medicina da Universidade de São Paulo, APROVOU / TOMOU CIÊNCIA na sessão datada de 17/08/2011 o protocolo acima.

A CAPPesq em obediência à Resolução CNS 196/96, solicita ao pesquisador (a) s elaboração de relatório parcial e final.

No caso de relatório parcial é necessário informar o tempo previsto para a conclusão do protocolo e breve resumo dos resultados obtidos.

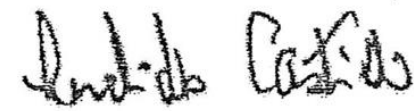

PROF. DR. EUCLIDES AYRES DE CASTILHO Coordenador

Comissão de Ética para Análise de Projetos de Pesquisa - CAPPesq 
Anexo 3 - Frequência dos alelos HLA locus A e comparação entre os grupos

\begin{tabular}{|c|c|c|c|c|c|c|c|c|c|c|c|}
\hline \multirow[t]{2}{*}{ HLA } & \multicolumn{2}{|c|}{ Asma Alérgica } & \multicolumn{2}{|c|}{ Asma não alérgica } & \multicolumn{2}{|c|}{ Controle } & \multirow{2}{*}{\multicolumn{2}{|c|}{ Valor-p }} & \multirow{2}{*}{$\begin{array}{c}\text { Asma alérgica } x \\
\text { Asma não alérgica }\end{array}$} & \multirow{2}{*}{$\begin{array}{c}\text { Asma alérgica } x \\
\text { Controle }\end{array}$} & \multirow{2}{*}{$\begin{array}{c}\text { Asma não alérgica } \mathrm{x} \\
\text { Controle }\end{array}$} \\
\hline & $\mathbf{N}$ & $\%$ & $\mathbf{N}$ & $\%$ & $\mathbf{N}$ & $\%$ & & & & & \\
\hline$A^{*} 01$ & 6 & 10,71 & 8 & 15,09 & 52 & 17,51 & 0,436 & 1 & 0,989 & 0,625 & 0,989 \\
\hline$A^{*} 02$ & 17 & 30,36 & 28 & 52,83 & 116 & 39,06 & 0,052 & 1 & 0,052 & 0,218 & 0,121 \\
\hline$A^{*} 03$ & 12 & 21,43 & 8 & 15,09 & 50 & 16,84 & 0,640 & 1 & 1,000 & 1,000 & 1,000 \\
\hline$A^{*} 11$ & 6 & 10,71 & 4 & 7,55 & 35 & 11,78 & 0,661 & 1 & 1,000 & 1,000 & 1,000 \\
\hline$A^{*} 23$ & 10 & 17,86 & 6 & 11,32 & 37 & 12,46 & 0,504 & 1 & 0,826 & 0,826 & 0,826 \\
\hline$A^{*} 24$ & 9 & 16,07 & 9 & 16,98 & 57 & 19,19 & 0,821 & 1 & 1,000 & 1,000 & 1,000 \\
\hline$A * 25$ & 0 & 0,00 & 1 & 1,89 & 11 & 3,70 & 0,404 & 2 & 0,972 & 0,673 & 1,000 \\
\hline$A^{*} 26$ & 4 & 7,14 & 3 & 5,66 & 16 & 5,39 & 0,830 & 2 & 1,000 & 1,000 & 1,000 \\
\hline$A^{*} 29$ & 8 & 14,29 & 4 & 7,55 & 29 & 9,76 & 0,473 & 1 & 0,784 & 0,784 & 0,800 \\
\hline$A^{*} 30$ & 8 & 14,29 & 5 & 9,43 & 37 & 12,46 & 0,736 & 1 & 1,000 & 1,000 & 1,000 \\
\hline$A^{*} 31$ & 5 & 8,93 & 5 & 9,43 & 26 & 8,75 & 0,960 & 2 & 1,000 & 1,000 & 1,000 \\
\hline$A^{*} 32$ & 4 & 7,14 & 3 & 5,66 & 14 & 4,71 & 0,708 & 2 & 1,000 & 1,000 & 1,000 \\
\hline$A^{*} 33$ & 6 & 10,71 & 4 & 7,55 & 26 & 8,75 & 0,845 & 2 & 1,000 & 1,000 & 1,000 \\
\hline$A^{*} 34$ & 2 & 3,57 & 1 & 1,89 & 4 & 1,35 & 0,357 & 2 & 1,000 & 0,730 & 1,000 \\
\hline$A^{*} 36$ & 1 & 1,79 & 0 & 0,00 & 2 & 0,67 & 0,610 & 2 & 1,000 & 1,000 & 1,000 \\
\hline$A^{*} 43$ & 0 & 0,00 & 1 & 1,89 & 0 & 0,00 & 0,131 & 2 & 0,972 & 1,000 & 0,454 \\
\hline$A^{*} 66$ & 1 & 1,79 & 0 & 0,00 & 3 & 1,01 & 0,715 & 2 & 1,000 & 1,000 & 1,000 \\
\hline$A^{*} 68$ & 9 & 16,07 & 5 & 9,43 & 31 & 10,44 & 0,430 & 1 & 0,667 & 0,667 & 0,825 \\
\hline$A^{*} 69$ & 0 & 0,00 & 1 & 1,89 & 1 & 0,34 & 0,263 & 2 & 0,972 & 1,000 & 0,841 \\
\hline$A^{*} 74$ & 0 & 0,00 & 3 & 5,66 & 12 & 4,04 & 0,169 & 2 & 0,335 & 0,453 & 0,483 \\
\hline
\end{tabular}

'Teste qui-quadrado de Pearson; ${ }^{2}$ Teste exato de Fisher; Post hoc corrigido pelo método de Holm (Bonferroni sequencial) 
Anexo 4 - Frequência dos alelos HLA locus B e comparação entre os grupos

\begin{tabular}{|c|c|c|c|c|c|c|c|c|c|c|c|}
\hline \multirow[t]{2}{*}{ HLA } & \multicolumn{2}{|c|}{ Asma Alérgica } & \multicolumn{2}{|c|}{ Asma não alérqica } & \multicolumn{2}{|c|}{ Controle } & \multirow[b]{2}{*}{ Valor-p } & \multirow{2}{*}{\multicolumn{2}{|c|}{$\begin{array}{c}\text { Asma alérgica } x \\
\text { Asma não alérgica }\end{array}$}} & \multirow{2}{*}{$\begin{array}{c}\text { Asma alérgica } \\
\text { x Controle }\end{array}$} & \multirow{2}{*}{$\begin{array}{c}\text { Asma não alérgica } \\
\text { x Controle }\end{array}$} \\
\hline & $\mathbf{N}$ & $\%$ & $\mathbf{N}$ & $\%$ & $\mathbf{N}$ & $\%$ & & & & & \\
\hline $\mathrm{B}^{*} 07$ & 7 & 12,50 & 10 & 18,87 & 32 & 10,77 & 0,248 & 1 & 0,719 & 0,719 & 0,285 \\
\hline $\mathrm{B}^{\star} 08$ & 3 & 5,36 & 9 & 16,98 & 26 & 8,75 & 0,114 & 2 & 0,158 & 0,595 & 0,158 \\
\hline$B^{*} 13$ & 0 & 0,00 & 1 & 1,89 & 12 & 4,04 & 0,299 & 2 & 0,972 & 0,679 & 0,972 \\
\hline$B * 14$ & 8 & 14,29 & 2 & 3,77 & 36 & 12,12 & 0,158 & 1 & 0,216 & 0,653 & 0,216 \\
\hline$B * 15$ & 10 & 17,86 & 7 & 13,21 & 60 & 20,20 & 0,476 & 1 & 1,000 & 1,000 & 0,699 \\
\hline$B * 18$ & 4 & 7,14 & 4 & 7,55 & 30 & 10,10 & 0,788 & 2 & 1,000 & 1,000 & 1,000 \\
\hline$B * 27$ & 1 & 1,79 & 1 & 1,89 & 11 & 3,70 & 0,904 & 2 & 1,000 & 1,000 & 1,000 \\
\hline$B * 35$ & 13 & 23,21 & 12 & 22,64 & 70 & 23,57 & 0,989 & 1 & 1,000 & 1,000 & 1,000 \\
\hline$B * 37$ & 1 & 1,79 & 2 & 3,77 & 8 & 2,69 & 0,776 & 2 & 1,000 & 1,000 & 1,000 \\
\hline$B * 38$ & 0 & 0,00 & 2 & 3,77 & 9 & 3,03 & 0,415 & 2 & 0,702 & 0,729 & 0,729 \\
\hline$B * 39$ & 1 & 1,79 & 6 & 11,32 & 19 & 6,40 & 0,128 & 2 & 0,168 & 0,442 & 0,442 \\
\hline$B * 40$ & 4 & 7,14 & 5 & 9,43 & 31 & 10,44 & 0,745 & 1 & 1,000 & 1,000 & 1,000 \\
\hline$B * 41$ & 3 & 5,36 & 1 & 1,89 & 8 & 2,69 & 0,617 & 2 & 1,000 & 1,000 & 1,000 \\
\hline$B * 42$ & 4 & 7,14 & 2 & 3,77 & 5 & 1,68 & 0,040 & 2 & 0,679 & 0,116 & 0,574 \\
\hline$B * 44$ & 14 & 25,00 & 12 & 22,64 & 53 & 17,85 & 0,380 & 1 & 0,816 & 0,631 & 0,816 \\
\hline$B * 45$ & 5 & 8,93 & 2 & 3,77 & 11 & 3,70 & 0,251 & 2 & 0,878 & 0,450 & 1,000 \\
\hline$B * 47$ & 0 & 0,00 & 0 & 0,00 & 4 & 1,35 & 1,000 & 2 & 1,000 & 1,000 & 1,000 \\
\hline$B * 48$ & 0 & 0,00 & 3 & 5,66 & 2 & 0,67 & 0,031 & 2 & 0,223 & 1,000 & 0,079 \\
\hline$B * 49$ & 1 & 1,79 & 0 & 0,00 & 16 & 5,39 & 0,164 & 2 & 1,000 & 0,983 & 0,434 \\
\hline$B * 50$ & 4 & 7,14 & 5 & 9,43 & 15 & 5,05 & 0,333 & 2 & 1,000 & 1,000 & 0,609 \\
\hline$B * 51$ & 7 & 12,50 & 7 & 13,21 & 47 & 15,82 & 0,754 & 1 & 1,000 & 1,000 & 1,000 \\
\hline$B * 52$ & 4 & 7,14 & 3 & 5,66 & 8 & 2,69 & 0,130 & 2 & 1,000 & 0,315 & 0,447 \\
\hline$B * 53$ & 5 & 8,93 & 1 & 1,89 & 14 & 4,71 & 0,263 & 2 & 0,601 & 0,601 & 0,710 \\
\hline$B^{\star} 54$ & 0 & 0,00 & 0 & 0,00 & 1 & 0,34 & 1,000 & 2 & 1,000 & 1,000 & 1,000 \\
\hline$B * 55$ & 1 & 1,79 & 0 & 0,00 & 7 & 2,36 & 0,843 & 2 & 1,000 & 1,000 & 1,000 \\
\hline$B^{\star} 57$ & 2 & 3,57 & 1 & 1,89 & 20 & 6,73 & 0,364 & 2 & 1,000 & 1,000 & 0,666 \\
\hline$B * 58$ & 6 & 10,71 & 1 & 1,89 & 14 & 4,71 & 0,111 & 2 & 0,320 & 0,320 & 0,710 \\
\hline$B^{*} 73$ & 0 & 0,00 & 1 & 1,89 & 1 & 0,34 & 0,263 & 2 & 0,972 & 1,000 & 0,841 \\
\hline$B * 81$ & 2 & 3,57 & 1 & 1,89 & 5 & 1,68 & 0,602 & 2 & 1,000 & 0,922 & 1,000 \\
\hline
\end{tabular}

${ }^{1}$ Teste qui-quadrado de Pearson; ${ }^{2}$ Teste exato de Fisher; Post hoc corrigido pelo método de Holm (Bonferroni sequencial) 
Anexo 5 - Frequência dos alelos HLA locus C e comparação entre os grupos

\begin{tabular}{|c|c|c|c|c|c|c|c|c|c|c|c|}
\hline \multirow[t]{2}{*}{ HLA } & \multicolumn{2}{|c|}{ Asma Alérgica } & \multicolumn{2}{|c|}{ Asma não alérgica } & \multicolumn{2}{|c|}{ Controle } & \multirow[b]{2}{*}{ Valor-p } & \multirow{2}{*}{\multicolumn{2}{|c|}{$\begin{array}{c}\text { Asma alérgica } x \\
\text { Asma não alérgica }\end{array}$}} & \multirow{2}{*}{$\begin{array}{c}\text { Asma alérgica } \\
x \text { Controle }\end{array}$} & \multirow{2}{*}{$\begin{array}{c}\text { Asma não alérgica } \\
\text { x Controle }\end{array}$} \\
\hline & $\mathbf{N}$ & $\%$ & $\mathbf{N}$ & $\%$ & $\mathbf{N}$ & $\%$ & & & & & \\
\hline$C^{*} 01$ & 2 & 3,57 & 1 & 1,89 & 14 & 4,73 & 0,786 & 2 & 1,000 & 1,000 & 1,000 \\
\hline $\mathrm{C}^{*} 02$ & 7 & 12,50 & 6 & 11,32 & 31 & 10,47 & 0,899 & 1 & 1,000 & 1,000 & 1,000 \\
\hline $\mathrm{C}^{*} 03$ & 14 & 25,00 & 8 & 15,09 & 68 & 22,97 & 0,386 & 1 & 0,593 & 0,742 & 0,593 \\
\hline$C^{*} 04$ & 16 & 28,57 & 14 & 26,42 & 90 & 30,41 & 0,828 & 1 & 1,000 & 1,000 & 1,000 \\
\hline$C^{*} 05$ & 9 & 16,07 & 5 & 9,43 & 30 & 10,14 & 0,398 & 1 & 0,601 & 0,583 & 0,876 \\
\hline$C^{*} 06$ & 12 & 21,43 & 7 & 13,21 & 54 & 18,24 & 0,527 & 1 & 0,774 & 0,774 & 0,774 \\
\hline$C^{*} 07$ & 17 & 30,36 & 23 & 43,40 & 103 & 34,80 & 0,341 & 1 & 0,474 & 0,520 & 0,474 \\
\hline $\mathrm{C}^{*} 08$ & 10 & 17,86 & 4 & 7,55 & 40 & 13,51 & 0,281 & 1 & 0,324 & 0,456 & 0,456 \\
\hline$C^{*} 12$ & 3 & 5,36 & 9 & 16,98 & 33 & 11,15 & 0,155 & 1 & 0,158 & 0,379 & 0,379 \\
\hline$C^{*} 14$ & 2 & 3,57 & 1 & 1,89 & 20 & 6,76 & 0,365 & 2 & 1,000 & 1,000 & 0,666 \\
\hline$C^{*} 15$ & 4 & 7,14 & 5 & 9,43 & 25 & 8,45 & 0,916 & 2 & 1,000 & 1,000 & 1,000 \\
\hline$C^{*} 16$ & 8 & 14,29 & 9 & 16,98 & 29 & 9,80 & 0,240 & 1 & 0,698 & 0,631 & 0,366 \\
\hline$C^{*} 17$ & 6 & 10,71 & 3 & 5,66 & 10 & 3,38 & 0,040 & 2 & 0,854 & 0,083 & 0,854 \\
\hline$C^{*} 18$ & 1 & 1,79 & 0 & 0,00 & 8 & 2,70 & 0,852 & 2 & 1,000 & 1,000 & 1,000 \\
\hline
\end{tabular}

${ }^{1}$ Teste qui-quadrado de Pearson; ${ }^{2}$ Teste exato de Fisher; Post hoc corrigido pelo método de Holm (Bonferroni sequencial) 
Anexo 6- Frequência dos alelos HLA locus DR e comparação entre os grupos

\begin{tabular}{|c|c|c|c|c|c|c|c|c|c|c|c|}
\hline \multirow[t]{2}{*}{ HLA } & \multicolumn{2}{|c|}{$\begin{array}{l}\text { Asma } \\
\text { Alérgica }\end{array}$} & \multicolumn{2}{|c|}{$\begin{array}{l}\text { Asma não } \\
\text { alérgica }\end{array}$} & \multicolumn{2}{|c|}{ Controle } & \multirow{2}{*}{\multicolumn{2}{|c|}{$\begin{array}{l}\text { Valor- } \\
\mathbf{p}\end{array}$}} & \multirow{2}{*}{$\begin{array}{l}\text { Asma alérgica } \\
\text { x Asma não } \\
\text { alérgica }\end{array}$} & \multirow{2}{*}{$\begin{array}{c}\text { Asma } \\
\text { alérgica x } \\
\text { Controle }\end{array}$} & \multirow{2}{*}{$\begin{array}{c}\text { Asma não alérgica } \\
\text { x Controle }\end{array}$} \\
\hline & $\mathbf{N}$ & $\%$ & $\mathbf{N}$ & $\%$ & $\mathbf{N}$ & $\%$ & & & & & \\
\hline $\mathrm{DRB} 1{ }^{*} 01$ & 4 & 7,14 & 8 & 15,09 & 58 & 19,53 & 0,072 & 1 & 0,370 & 0,076 & 0,447 \\
\hline DRB1*03 & 15 & 26,79 & 10 & 18,87 & 62 & 20,88 & 0,545 & 1 & 0,977 & 0,977 & 0,977 \\
\hline DRB1*04 & 10 & 17,86 & 12 & 22,64 & 64 & 21,55 & 0,794 & 1 & 1,000 & 1,000 & 1,000 \\
\hline DRB1*07 & 14 & 25,00 & 14 & 26,42 & 71 & 23,91 & 0,920 & 1 & 1,000 & 1,000 & 1,000 \\
\hline DRB1*08 & 9 & 16,07 & 6 & 11,32 & 36 & 12,12 & 0,686 & 1 & 1,000 & 1,000 & 1,000 \\
\hline DRB1*09 & 3 & 5,36 & 3 & 5,66 & 9 & 3,03 & 0,454 & 2 & 1,000 & 1,000 & 1,000 \\
\hline DRB1*10 & 2 & 3,57 & 1 & 1,89 & 12 & 4,04 & 0,912 & 2 & 1,000 & 1,000 & 1,000 \\
\hline DRB1*11 & 14 & 25,00 & 13 & 24,53 & 50 & 16,84 & 0,195 & 1 & 0,955 & 0,437 & 0,437 \\
\hline DRB1*12 & 2 & 3,57 & 6 & 11,32 & 16 & 5,39 & 0,194 & 2 & 0,361 & 0,749 & 0,361 \\
\hline DRB $1 * 13$ & 22 & 39,29 & 11 & 20,75 & 75 & 25,25 & 0,054 & 1 & 0,093 & 0,093 & 0,484 \\
\hline DRB1*14 & 6 & 10,71 & 6 & 11,32 & 28 & 9,43 & 0,889 & 1 & 1,000 & 1,000 & 1,000 \\
\hline DRB1*15 & 5 & 8,93 & 8 & 15,09 & 57 & 19,19 & 0,159 & 1 & 0,642 & 0,172 & 0,642 \\
\hline DRB1*16 & 1 & 1,79 & 4 & 7,55 & 19 & 6,40 & 0,355 & 2 & 0,593 & 0,593 & 0,763 \\
\hline
\end{tabular}

${ }^{1}$ Teste qui-quadrado de Pearson; ${ }^{2}$ Teste exato de Fisher; Post hoc corrigido pelo método de Holm (Bonferroni sequencial) 
Anexo 7 - Frequência dos alelos HLA locus DQ e comparação entre os grupos

\begin{tabular}{|c|c|c|c|c|c|c|c|c|c|c|c|}
\hline \multirow[t]{2}{*}{ HLA } & \multicolumn{2}{|c|}{ Asma Alérgica } & \multicolumn{2}{|c|}{ Asma não alérgica } & \multicolumn{2}{|c|}{ Controle } & \multirow[b]{2}{*}{ Valor-p } & \multirow{2}{*}{\multicolumn{2}{|c|}{$\begin{array}{l}\text { Asma alérgica } x \\
\text { Asma não alérgica }\end{array}$}} & \multirow{2}{*}{$\begin{array}{c}\text { Asma alérgica } \\
x \text { Controle }\end{array}$} & \multirow{2}{*}{$\begin{array}{c}\text { Asma não alérgica } \\
\text { x Controle }\end{array}$} \\
\hline & $\mathbf{N}$ & $\%$ & $\mathbf{N}$ & $\%$ & $\mathbf{N}$ & $\%$ & & & & & \\
\hline$D Q A^{*} 01$ & 34 & 60,71 & 30 & 56,60 & 197 & 66,33 & 0,331 & 1 & 0,835 & 0,835 & 0,516 \\
\hline $\mathrm{DQA}^{*} 02$ & 14 & 25,00 & 14 & 26,42 & 66 & 22,22 & 0,752 & 1 & 1,000 & 1,000 & 1,000 \\
\hline$D Q A^{*} 03$ & 15 & 26,79 & 16 & 30,19 & 72 & 24,24 & 0,635 & 1 & 1,000 & 1,000 & 1,000 \\
\hline$D Q A^{\star} 04$ & 9 & 16,07 & 5 & 9,43 & 38 & 12,79 & 0,584 & 1 & 0,902 & 0,985 & 0,985 \\
\hline DQA*05 & 25 & 44,64 & 24 & 45,28 & 124 & 41,75 & 0,844 & 1 & 1,000 & 1,000 & 1,000 \\
\hline$D Q A^{*} 06$ & 1 & 1,79 & 1 & 1,89 & 3 & 1,01 & 0,406 & 2 & 1,000 & 1,000 & 1,000 \\
\hline$D_{Q}{ }^{\star} 02$ & 27 & 48,21 & 21 & 39,62 & 115 & 38,72 & 0,412 & 1 & 0,733 & 0,552 & 0,901 \\
\hline $\mathrm{DQB}^{\star} 03$ & 26 & 46,43 & 32 & 60,38 & 131 & 44,11 & 0,091 & 1 & 0,289 & 0,749 & 0,086 \\
\hline DQB*04 & 9 & 16,07 & 5 & 9,43 & 44 & 14,81 & 0,540 & 1 & 0,895 & 0,895 & 0,895 \\
\hline $\mathrm{DQB}^{*} 05$ & 12 & 21,43 & 17 & 32,08 & 109 & 36,70 & 0,082 & 1 & 0,417 & 0,082 & 0,518 \\
\hline DQB ${ }^{*} 06$ & 24 & 42,86 & 17 & 32,08 & 113 & 38,05 & 0,509 & 1 & 0,736 & 0,814 & 0,814 \\
\hline
\end{tabular}

1Teste qui-quadrado de Pearson; ${ }^{2}$ Teste exato de Fisher; Post hoc corrigido pelo método de Holm (Bonferroni sequencial) 
Anexo 8 - Frequência dos alelos HLA locus DP e comparação entre os grupos

\begin{tabular}{|c|c|c|c|c|c|c|c|c|c|c|c|}
\hline \multirow[t]{2}{*}{ HLA } & \multicolumn{2}{|c|}{ Asma Alérgica } & \multicolumn{2}{|c|}{ Asma não alérgica } & \multicolumn{2}{|c|}{ Controle } & \multirow{2}{*}{\multicolumn{2}{|c|}{ Valor-p }} & \multirow{2}{*}{$\begin{array}{l}\text { Asma alérgica } \\
\text { x Asma não } \\
\text { alérgica }\end{array}$} & \multirow{2}{*}{$\begin{array}{c}\text { Asma } \\
\text { alérgica } \mathrm{x} \\
\text { Controle }\end{array}$} & \multirow{2}{*}{$\begin{array}{c}\text { Asma não } \\
\text { alérgica x } \\
\text { Controle }\end{array}$} \\
\hline & $\mathbf{N}$ & $\%$ & $\mathbf{N}$ & $\%$ & $\mathbf{N}$ & $\%$ & & & & & \\
\hline $\mathrm{DPA} 1{ }^{*} 01$ & 49 & 87,50 & 46 & 86,79 & 134 & 85,90 & 0,952 & 1 & 1,000 & 1,000 & 1,000 \\
\hline $\mathrm{DPA} 1{ }^{*} 02$ & 26 & 46,43 & 24 & 45,28 & 78 & 50,00 & 0,798 & 1 & 1,000 & 1,000 & 1,000 \\
\hline $\mathrm{DPA} 1{ }^{*} 03$ & 7 & 12,50 & 4 & 7,55 & 4 & 2,56 & 0,013 & 2 & 0,391 & 0,026 & 0,229 \\
\hline $\mathrm{DPA} 1{ }^{*} 04$ & 2 & 3,57 & 0 & 0,00 & 4 & 2,56 & 0,455 & 2 & 1,000 & 1,000 & 1,000 \\
\hline $\mathrm{DPB} 1{ }^{*} 01$ & 18 & 32,14 & 10 & 18,87 & 37 & 23,72 & 0,256 & 1 & 0,339 & 0,435 & 0,465 \\
\hline $\mathrm{DPB} 1{ }^{*} 02$ & 20 & 35,71 & 14 & 26,42 & 48 & 30,77 & 0,575 & 1 & 0,885 & 0,993 & 0,993 \\
\hline $\mathrm{DPB} 1{ }^{*} 03$ & 7 & 12,50 & 10 & 18,87 & 29 & 18,59 & 0,557 & 1 & 0,893 & 0,893 & 0,964 \\
\hline $\mathrm{DPB} 1{ }^{*} 04$ & 25 & 44,64 & 32 & 60,38 & 93 & 59,62 & 0,126 & 1 & 0,200 & 0,159 & 0,922 \\
\hline $\mathrm{DPB} 1{ }^{*} 05$ & 1 & 1,79 & 1 & 1,89 & 4 & 2,56 & 1,000 & 2 & 1,000 & 1,000 & 1,000 \\
\hline $\mathrm{DPB} 1{ }^{*} 06$ & 1 & 1,79 & 1 & 1,89 & 4 & 2,56 & 1,000 & 2 & 1,000 & 1,000 & 1,000 \\
\hline $\mathrm{DPB} 1{ }^{*} 09$ & 1 & 1,79 & 0 & 0,00 & 3 & 1,92 & 0,821 & 2 & 1,000 & 1,000 & 1,000 \\
\hline $\mathrm{DPB}^{*}{ }^{*} 10$ & 2 & 3,57 & 2 & 3,77 & 8 & 5,13 & 1,000 & 2 & 1,000 & 1,000 & 1,000 \\
\hline DPB1*11 & 4 & 7,14 & 3 & 5,66 & 3 & 1,92 & 0,115 & 2 & 1,000 & 0,243 & 0,345 \\
\hline $\mathrm{DPB}^{*}{ }^{*} 13$ & 4 & 7,14 & 1 & 1,89 & 8 & 5,13 & 0,420 & 2 & 1,000 & 1,000 & 1,000 \\
\hline DPB1*14 & 3 & 5,36 & 2 & 3,77 & 8 & 5,13 & 1,000 & 2 & 1,000 & 1,000 & 1,000 \\
\hline $\mathrm{DPB}^{*}{ }^{*} 16$ & 0 & 0,00 & 0 & 0,00 & 3 & 1,92 & 0,570 & 2 & 1,000 & 1,000 & 1,000 \\
\hline DPB1*17 & 4 & 7,14 & 7 & 13,21 & 14 & 8,97 & 0,531 & 1 & 0,880 & 0,880 & 0,880 \\
\hline $\mathrm{DPB}^{*}{ }^{*} 18$ & 1 & 1,79 & 2 & 3,77 & 1 & 0,64 & 0,127 & 2 & 0,919 & 0,919 & 0,477 \\
\hline DPB1*20 & 2 & 3,57 & 0 & 0,00 & 1 & 0,64 & 0,217 & 2 & 0,992 & 0,513 & 1,000 \\
\hline DPB1*23 & 0 & 0,00 & 1 & 1,89 & 0 & 0,00 & 0,200 & 2 & 0,972 & 1,000 & 0,761 \\
\hline
\end{tabular}


Continua -Anexo 8

\begin{tabular}{|c|c|c|c|c|c|c|c|c|c|c|c|}
\hline \multirow[t]{2}{*}{ HLA } & \multicolumn{2}{|c|}{ Asma Alérgica } & \multicolumn{2}{|c|}{ Asma não alérgica } & \multicolumn{2}{|c|}{ Controle } & \multirow{2}{*}{\multicolumn{2}{|c|}{ Valor-p }} & \multirow{2}{*}{$\begin{array}{c}\text { Asma alérgica } \\
\text { x Asma não } \\
\text { alérgica }\end{array}$} & \multirow{2}{*}{$\begin{array}{c}\text { Asma } \\
\text { alérgica x } \\
\text { Controle }\end{array}$} & \multirow{2}{*}{$\begin{array}{c}\text { Asma não } \\
\text { alérgica x } \\
\text { Controle }\end{array}$} \\
\hline & $\mathbf{N}$ & $\%$ & $\mathbf{N}$ & $\%$ & $\mathbf{N}$ & $\%$ & & & & & \\
\hline $\mathrm{DPB} 1 * 27$ & 0 & 0,00 & 0 & 0,00 & 3 & 1,92 & 0,570 & 2 & 1,000 & 1,000 & 1,000 \\
\hline $\mathrm{DPB} 1 * 29$ & 1 & 1,79 & 0 & 0,00 & 0 & 0,00 & 0,411 & 2 & 1,000 & 0,792 & 1,000 \\
\hline DPB1*34 & 1 & 1,79 & 0 & 0,00 & 0 & 0,00 & 0,411 & 2 & 1,000 & 0,792 & 1,000 \\
\hline DPB1*39 & 1 & 1,79 & 0 & 0,00 & 1 & 0,64 & 0,6542 & 2 & 1,000 & 1,000 & 1,000 \\
\hline $\mathrm{DPB} 1 * 40$ & 0 & 0,00 & 1 & 1,89 & 0 & 0,00 & 0,200 & 2 & 0,972 & 1,000 & 0,761 \\
\hline DPB1*45 & 0 & 0,00 & 0 & 0,00 & 1 & 0,64 & 1,000 & 2 & 1,000 & 1,000 & 1,000 \\
\hline DPB1*47 & 1 & 1,79 & 0 & 0,00 & 0 & 0,00 & 0,411 & 2 & 1,000 & 0,792 & 1,000 \\
\hline $\mathrm{DPB} 1 * 49$ & 0 & 0,00 & 1 & 1,89 & 0 & 0,00 & 0,200 & 2 & 0,972 & 1,000 & 0,761 \\
\hline DPB1*55 & 0 & 0,00 & 1 & 1,89 & 0 & 0,00 & 0,200 & 2 & 0,972 & 1,000 & 0,761 \\
\hline DPB1*85 & 0 & 0,00 & 0 & 0,00 & 1 & 0,64 & 1,000 & 2 & 1,000 & 1,000 & 1,000 \\
\hline DPB1*86 & 0 & 0,00 & 0 & 0,00 & 1 & 0,64 & 1,0002 & 2 & 1,000 & 1,000 & 1,000 \\
\hline DPB1*105 & 7 & 12,50 & 3 & 5,66 & 5 & 3,21 & 0,036 & 2 & 0,644 & 0,049 & 0,644 \\
\hline DPB1*131 & 1 & 1,79 & 0 & 0,00 & 5 & 3,21 & 0,628 & 2 & 1,000 & 1,000 & 0,998 \\
\hline DPB1*148 & 0 & 0,00 & 0 & 0,00 & 1 & 0,64 & 1,0002 & 2 & 1,000 & 1,000 & 1,000 \\
\hline
\end{tabular}

${ }^{1}$ Teste qui-quadrado de Pearson; ${ }^{2}$ Teste exato de Fisher; Post hoc corrigido pelo método de Holm (Bonferroni sequencial) 
Agondi RC, Barros MT, Rizzo LV, Kalil J, Giavina-Bianchi P. Allergic asthma in patients with common variable immunodeficiency. Allergy. 2010;65:510-5.

Apostolakis J, Toumbis M, Konstantopoulos K, Angnostakis J, Georgoulias V, Fessas PH, Zervas J.HLA antigens and asthma in Greeks. Respir Med.1996; $90: 201-4$.

Aron Y, Desmazes-Dufeu N, Matran R et al. Evidence of a Strong, positive association betwen atopy and the HLA class II alleles DR4 and DR7.Clin Exp Allergy.1996; 26:821-8.

Bousquet J, Chanez P, Chanal I, Michel F-B. Comparison between RAST and Pharmacia CAP System: A new automated specific IgE assay. J Allergy Clin Immunol.1990; 85:1039-43.

Breiman L, Friedman JH, Olshen RA, Stone CJ. Classification and regression trees Wadsworth. 1984.

Brinke A T; Dissel J T v; Sterk P J, et al. Persistent airflow limitation in adultonset nonatopic asthma is associated with serologic evidence of Chlamydia pneumonia infection.J Allergy Clin Immunol. 2001; 107:449-54.

Brostoff J, Mowbray JF, Kapoor A, Hollowell SJ, Rudolf M, Saunders KB. 80\% of patients with intrinsic asthma are homozygous for HLA W6- is intrinsic asthma are a recessive disease? Lancet.1976; 2:872-3.

Brunner E, Munzel U.The nonparametric Behrens-Fisher Problem: Asymptotic Theory and a Small-SampleApproximation. Biom J.2000; 42:17-25. 
Busse WW, Calhoun WF, Sedgwick JD. Mechanism of airway inflammation in asthma. Am Rev Respir Dis. 1993; 147:S20-4.

Caraballo L, Marrugo J, Jimenez S, et al. Frequency of DPB1*0401 is significantly decreased in patients with allergic asthma in a mulatto population. Hum Immunol .1991; 32:157-61.

Charpin D, Ramadour M, Lanteaume, Vervloet D. Triggers in intrinsic asthma in the EGEA study.J Asthma. 2003; 40: 87-91.

Choi JH, Lee $\mathrm{KW}$, Oh HB, et al. HLA association in aspirin-intolerant asthma: DPB10301 as a strong marker in a Korean population.J Allergy Clin Immunol. 2004;113:562-4.

Ciprandi G, De Amici M, Caimmi S, Marseglia A, Marchi A, Castellazzi AM, Marseglia G. Soluble serum HLA-G in children with allergic rhinitis and asthma. J Biol Regul Homeost Agents.2010; 24:221-4.

Comert S, Celebioglu E, Yucel T, Erdogan T, Karakaya G, Onerci M, Kalyoncu AF. Aspirin $300 \mathrm{mg} /$ day is effective for treating aspirin-exacerbated respiratory disease. Allergy.2013;68: 1443-51.

Comi A L, Tedeschi A, Lorini M, Miadonna A. Novel clinical and serological aspects in non -allergic asthma. Respir Med. 2007; 101:2526-33.

Dekker JW, Nizankowska E, Schmitz-Schumann M, et al. Aspirin-induced asthma and HLA-DRB1 and HLA-DPB1 genotypes. Clin Exp Allergy.1997; 27:574-7.

Demoly P, Piette V, Bousquet J. In vivo methods for study of allergy: skin tests, techniques and interpretation. In: Adkinson Jr, NF; Yunginger, JW; Busse, WW; Bochner, BS; Holgate, ST; Simons, FER. Middleton's Allergy: Principles and Practice. St. Louis: CV Mosby. 2003;631-43. 
DiCiccio TJ, Efron B. Bootstrap confidence intervals (with Discussion). Statistical Sscience.1996; 11:189-228.

Dolan CM, Fraher KE, Bleecker ER, Borish L, Chipps B et al. TENOR Study Group.Design and baseline characteristics of the epidemiology and natural history of asthma: Outcomes and Treatment Regimens (TENOR) study: a large cohort of patients with severe or difficult-to-treat asthma. Ann Allergy Asthma Immunol. 2004;92:32-9.

Daher S, Galvão C, Abe A, Cocco R. Diagnóstico em Doenças Alérgicas Mediadas por IgE.Rev bras alerg imunopatol.2009;3-8.

ENFUMOSA.The ENFUMOSA cross-sectional European multicentre study of the clinical phenotype of chronic severe asthma.European Network for Understanding Mechanisms of Severe Asthma. Eur Respir J.2003 22:470-7.

Fahy JV, Kim KW, Liu J, Boushey HA.Prominent neutrophilic inflammation in sputum from subjects with asthma exacerbation.J Allergy Clin Immunol.1995; 70128-1.

Flaherty DK, Geller M, Surfus JE, Leo GM, Reed CE, Rankin J. HLA antigen frequencies and natural history in Alternaria sensitive perennial nonallergic asthmatics. J Allergy Clin Immunol.1980; 66:408-16.

Gao J, Lin Y. Qiu C [HLA-DRB alleles polymorphism in susceptibility to asthma in Beijing Chinese. Zhonghua Yi Xue Za Zhi.1998; 78:591-4.

Gao J, Lin Y, Giu C et al. Association between HLA DQA1-DQB1 gene polymorphisms and susceptibiilty to asthma in northern Chinese Subjects. Chin Med J. 2003; 116:1078-82. 
Giavina-Bianchi P, Kalil J, Rizzo LV. Development of an animal model for allergic conjunctivitis: influence of genetic factors and allergen concentration on immune response. Acta Ophthalmol.2008; 86:670-5.

Giavina-Bianchi P, Agondi RC, Kalil J. Asthma studies should be phenotype specific. J Allergy Clin Immunol 2013; 131:1261-2.

Giavina-Bianchi P. Defining phenotypes in rhinitis: A step toward personalized medicine. J Allergy Clin Immunol.2015; 135:151-2.

Global Initiative for Asthma (GINA).Global strategy for asthma management and prevention. Bethesda, Md.: National Institutes of Health/Natioal Heart, Lung and Blood Institute of Health, 2012.

Green $\mathrm{RH}$, Bradding P. Subclinical phenotypes of asthma. Curr Opin Allergy Clin Immunol.2010; 10:1054-9.

Greeg, I. Asthma, edited by Clark TJH and Godfrey S, ch 1. Chapman and Hall, London. 1977.

Guo X, Ni P, Li L. Association between asthma and the polymorphism of HLADQ genes. Zhonghua Jie He He Hu Xi Za Zhi. 2001; 24:139-41.

Hallstrand T, Henderson WJ.Management of the Asthmatic Patient.Clinical Immunology Principles and Practice.2001:2nd.

Haldar P, Pavord ID, Shaw DE, Berry MA, Thomas M, Brightling CE, et al. Cluster analysis and clinical asthma phenotypes. Am J Respir Crit Care Med. 2008; 178:218-24. 
Henderson J, Granell R, Heron J, Sherriff A, Simpson A, Woodcock A, et al. Association of wheezing phenotypes in the first 6 years of life with atopy, lung function and airway responsiveness in mild-childhood. Thorax.2008; 63:974-80.

Hsieh KH, Shieh CC, Hsieh RP, Liu WJ. Association of HLA - DQw2 with Chinese childhood asthma. Tissue Antigens.1991; 38:181-2.

Huang LS, Hsieh KH, Liu SY.HLA and childhood asthma (author's transl). Zhonghua minguo weishengwu ji mianyixue zazhi.1981; 14:102-6.

IBGE. Pesquisa Nacional por Amostra de Domicilios - Sintese de Indicadores 2011: Notas técnicas. 2012.

ImmunoCAP ${ }^{\mathrm{TM}}$ Technology. Phadia- www.phadia.com.br

Ivkovic-Jurekovic I, Zunec R, Balog V, Grubic Z.The distribution of HLA alleles among children with atopic asthma in Croatia. Coll Antropol.2011; 35:1243-9.

Jatakanon A, Uasuf C, Maziak W, Lim S, Chung KF, Barnes PJ.Neutrophilic inflammation in severe persistent asthma.Am $J$ Respir Crit Care Med. 1999; 160:1532-9.

Jenkins H, Cherniack R, Szefler S, Covar R, Gelfand E, Spahn J.A comparison of the clinical characteristics of children and adults with severe asthma.Chest. 2003; 124:1318-24.

Johansson SGO, Hourihane JO'B, Bousquet $\mathrm{J}$ et al. Position Paper.A revise Nomenclature for allergy.An EEACl position statement from the EEACI nomenclature task force. Allergy.2001; 56:813-24.

Johansson SGO, Bieber T, Dahl R, Friedmann PS, Lanier BQ, Lockey RF, et al. Revised nomenclature for allergy for global use: report of the nomenclature review committee of the World Allergy Organization.J Allergy Clin Immunol. $2004 ; 113: 832-6$ 
Johansson SGOJ, Yman L. In vitro assays for immunoglobulin E.Methodology, indications and interpretation.Clin Rev Allergy.1988; 6:93-139.

Jones DH, May AG, Condemi JJ. HLA DR typing of aspirin sensitive asthmatics. Ann Allergy.1984; 52:87-9.

Juhn YJ, Kita H, Lee LA, Smith RW, Bagniewski SM, Weaver AL et al. Childhood asthma and human leukocyte antigen type. Tissue antigens. 2006;69:38-46.

Kim JH, Park BL, Cheong HS et al. HLA-DRA polymorphisms associated with risk of nasal polyposis in asthmatic patients. Am J Rhinol Allergy.2012; 26:12-7

Knutsen AP, Vijay HM, Kumar V. Kariuki B, Santiago LA, Graff R, Wofford JD et al. Mold-sensitivity in children with moderate-severe asthma is associated with HLA-DR and HLA-DQ.Allergy: European Journal of Allergy and Clinical Immunology.2010; 65:1367-75.

Kourilsky P, Truffa-Bachi P. Cytokine fields and the polarization of the immune response. TRENDS in Immunology.2001; 22:502-9.

Lamblin CL, Gosset P, Tillie-Leblond I, Saulnier F, Marquette CH, Wallaert B et al. Bronchial neutrophilia in patients with noninfectious status asthmaticus. Am J Respir Crit Care Med. 1998; 157:394-402.

Lara-Marquez ML, Yunis JJ, Layrisse Z, Ortega F, Carvallo-Gil E, Montagnani S, Makhatadze NJ, Pocino M, Granja C, Yunis E. Immunogenetics of atopic asthma: Association of DRB1*1101 DQA $1{ }^{*} 0501$ DQB1*0301 haplotype with Dermatophagoides spp -Sensitive asthma in a sample of the Venezuelan population. Clin Exp Allergy.1999; 29:60-71. 
Lasky-Su J, Himes BE, Raby BA et al.HLA-DQ strikes again: Genome-wide association study furher confirms HLA-DQ in the diagnosis of asthma among adults. Clin Exp Allergy.2012; 42:1724-33.

Leimgruber A, Peitrequin R, Mosimann B, Clayes $M$, Seppey Mn Jaccard $Y$, PĖcoud A. The Pharmacia CAP System: A new Assay for specific lgE. J Allergy Clin Immunol.1989; 83:176.

Leopold HC, Rynes S, Stoloff IL.Fluorescent antibody study for antinuclear antibodies in bronchial asthma.J Allergy.1965; 36:175-7.

Leung DYM, Nelson HS, Szefler SJ, Busse WW. Analyzing asthma phenotypes. J Allergy Clin Immunol.2004; 113:1-2.

Lidor Y, Topilsky M, Spitzer SA, Yehoshua H. Autoimmune antibodies in intrinsic (non-atopic) asthma . Ann Allergy.1980; 44: 296-8.

Li PK, Lai CK, Poon AS, et al. Lack of association between HLA-DQ and -DR genotypes and asthma in southern Chinese patients.Clin Exp Allergy.1995; 25:323-31.

Li X, Howard TD, Zheng SI. Genome-Wide association study of asthma identifies RAD50-IL13 and HLA DR/DQ regions.J Allergy Clin Immunol.2010; 125:328-35.

Lockey R. Asthma phenotypes: An Approach to the diagnosis and treatment of asthma.J Allergy Clin Immunol.2014; 2:682-5.

Martyn MB, Molis W, Jacobson R, Poland G, Weaver A, Juhn Y. Human leukocyte antigen type and progression from onset of symptoms to development of asthma.Allergy Asthma Proc. 2010; 31:120-5. 
Macek V, Sorli J, Kopriva S, Marin J. Persistent adenoviral infection and chronic airway obstruction in children.Am J Respir Crit Med .1994; 150:7-10.

Marsh DG, Meyers DA, Bias WB.The epidemiology and genetics of atopic allergy.N Engl J Med. 1981; 305:1551-9.

Mclntosh JC, Simecka JW, Ross SE, Davis JK, Miller EJ, Cassell GH.Infectioninduced airway fibrosis in two rat strains with differential susceptibility. Infect Immun. 1992; 60:2936-42.

Menz G, Ying S, Durham SR, Corrigan CJ, Robison DS, Hamid Q, Pfister R, Humbert M, Kay Ab. Molecular concepts of $\lg \mathrm{E}$ - initiated inflammation in atopic and nonatopic asthma. Allergy.1998; 53:15-21.

Miller MR, Hankinson J, Brusasco V, Burgos F, Casaburi R, Coates A, Crapo R, Enright P, van der Griten COM, Gistafsson P, Jensen R, Johnson DC, Macintyre N, Mckay R, Navajas D, Pedersen OF, Pellegrino R, Viegi G, Wanger J. Standardization of spirometry. Eu Resp J. 2005; 26:319-28.

Miranda C, Busacker BS, Balzar S, Trudeau J, Wenzel S. Distinguishing severe asthma phenotypes: Role of age at onset and eosinophilic inflammation. J Allergy Clin Immunol.2004;101-8.

Moffatt MF, Gut IG, Demenais F, Strachan DP, Bouzigon E, Heath S, et al. A large-scale, consortium-based genome wide association study of asthma. $N$ Engl J Med. 2010:23; 363:1211-21.

Molina C, Brun J, Colet M, Betail G, Delage J. Immunopathology of the bronchial mucosa in late onset asthma. Clin Allergy.1977; 7:137-45.

Moloney JR, Oliver TD.HLA antigens, nasal polyps and asthma. Clin Otolaryngol.1980; 5:183-9. 
Moore WC, Meyers DA, Wenzel SE, Teague WG, Li H, Li, X, et al. Identification of asthma phenotypes using cluster analysis in the Severe Asthma Research Program. Am J Respir Crit Care Med. 2010; $181: 315-23$.

Moraes ME, Fernandez-Viña M, Salatiel I, Tsai S, Moraes JR, Stastny P. HLA class II DNA typing in two Brazilian populations. Tissue Antigens. 1993 May; 41:238-42.

Morris MJ, Vaughan H, Lane DJ, Morris PJ.HLA in asthma.Monogr Allergy. 1977;11:30.

Morris MJ, Faux JA, Ting A, Morris PJ, Lane DJ. HLA-A, B and C and HLA-DR antigens in intrinsic and allergic asthma.Clin Allergy.1980; 10:173-9.

Mosbech H, Dirsen A, Madesen F, Stahl Skov P, Weeke B. House dust mite asthma. Correlation between allergen sensivity in various organs.Allergy.1987; 42:456-63.

Munthe-Kaas MC, Carlsen KL, Carlsen KH, Egeland T, Håland G, Devulapalli CS, Akselsen $\mathrm{H}$ et al.HLA Dr-Dq haplotypes and the TNFA-308 polymorphism: Associations with asthma and allergy .Allergy: European Journal of Allergy and Clinical Immunology.2007; 62: 991-8.

Nahm DH, Shin MJ, Yim H, Kang Y, Choi DC, Kim JK, Kim SS, Park HS. Increased levels of circulating autoantibodies to cultured human bronchial epithelial cell in adult patients with nonatopic asthma.J Korean Med Sci. 2001; 16: 407-10.

Noguchi E, Sakamoto $H$, Hirota $T$, et al. Genome-wide association study identifies HLA-DP as a susceptibility gene for pediatric asthma in Asian populations. PLoS Genet.2011;7. 
Mishra MN, Dudeja P, Gupta RK.A study on human leukocyte antigen class I molecules in paediatric bronchial asthma. Indian $J$ Biochem Biophys. 2014;51:160-3.

Ostergaard PA, Ericksen J. Association between HLA A1 / B8 in children with extrinsic asthma and IgA deficiency. Eur J Pediat. 1979; 131:263-70.

Parapanissiou E, Papastavrou T, Deligianniis A, Adam K, Kanakoudi F, Daniilidis $M$ et al. HLA antigens in Greek children with allergic bronchial asthma. Tissue Antigens.2005; 65:481-4.

Pastorello EA, Incorvaia C, Pravettoni V, Bonini S, Canonica GV, Ortolini C et al. A multicentric study on sensivity and specificity of a new in vitro test for measurement of IgE antibodies. Ann Allergy.1991; 67:365-70.

Pellegrio R, Viegi G, Brusasco V, Crapo RO, Burgos F, Casaburi R, Coates A, van der Griten, Gustafsson P, Hankinson J, Jensen R, Johnson DC, Macintyre N, McKay R, Miller MR, Navajas D, Pedersen OF, Wanger J. Interpretative strategies for lung function tests. Eur Respir J.2005; 26:948-68.

Platts-Mills TA.Local production of $\lg G$, $\lg A$ and $\lg E$ antibodies in grass pollen hay fever.J Immunol.1979; 122: 2218-25.

Pillai P, Corrigan CJ, Ying S. Airway Epithelium in atopic and nonatopic asthma: similarities and differences. Allergy.2011; 1-7.

Rackeman FM. A working classification of asthma.Am J Med.1947; 3:601-6.

Romagnani S. Regulation of the development of type 2 T-helper cells in allergy. Curr Opin Immunol.1994; 6:838-46. 
Romanet -Manent S, Charpin D, Magnam A, Lanteaume A, Vervloet D. Allergic vs nonallergic asthma: what makes the difference? Allergy .2002; 57: 607-13.

Santing RE, Olymulder CG, Zaagsma J, Meurs H. Relantionship among allergen-induce early and late phase airway obstructions, bronchial hyperreactivity and inflammation in conscious, unrestrained guinea pigs.J Allergy Clin Immunol.1994; 93:1021-30.

Settipane GA,Chafee FH.Nasal polyps in asthma and rhinitis.A review of 6,037 patients.J Allergy Clin Immunol.1977; 59:17-21.

Sibbald B,Turner-Warwick M. Factors influencing the prevalence ofasthma among first degree relatives of extrinsic and intrinsic asthmatics. Thorax.1979; 34:332-7.

Solé D, Wandalsen GF, Camelo-Nunes IC, Naspitz CK, ISAAC-Brazilian Group. Prevalence of symptoms of asthma, rhinitis and atopic eczema among Brazilian children and adolescents identified by International Study of Athma and Allergies in Childhood (ISAAC)-Phase 3. J Pediatr.2006; 82:341-6.

Sur S, Crotty TB, Kephart GM, Hyma BA, Colby TV, Reed CE, et al. Suddenonset fatal asthma.A distinct entity with few eosinophils and relatively more neutrophils in the airway submucosa? Am Rev Respir Dis. 1993; 148:713-9.

Szczeklik A, Nizankowska E, Serafin A, Dyczek A, DuplagaM, Musial J.Autoimmune phenomena in bronchial asthma with special reference to aspirin intolerance. Am J of Respir Crit Care Med.1995; 152:1753-6.

Specjalski K, Chelminska M. Pathogenesis of aspirin-induced of asthma. Pol Arch Med Wewn. 2006; 115:265-70. 
Tahan F, Patiroglu T.Plasma soluble human leukocyte antigen G levels in asthmatic children. Int Arch Allergy Immunol. 2006.141: 213-6.

TENOR Study Group. Borish L, Chips B, Deniz, Gujrathi S, Zheng B, Dolan CM. Total serum IgE levels in a large cohort of patients with severe or difficult-totreat asthma. Ann Allergy Asthma Immunol. 2005; 95: 247-53.

Thorsby E, Engeset A, So L. HL-A antigens and susceptibility to disease. A study of patients with acute lymphoblastic leukemia, Hodgkin's disease and childhood asthma. Tissue Antigens.1971;1:147-52.

Torio A, Sanchez-Guerrero I, Muro M, Herrero N, Pagán J, Minguela A, Marin L, Moya-Quiles MR, Sanchís MJ, Àlvarez-López MR. Analysis of the phenotype distribution of HLA class I and class II in atopic and non-atopic asthma patients. Eur J Immunogenet. 2000; 27:81-5.

Torio A, Sanchez-Guerrero I, Muro M et al. HLA class II genotypic frequencies in atopic asthma: association of DRB1 ${ }^{\star} 01-\mathrm{DQB} 1{ }^{*} 0501$ genotype with Artemisia vulgaris allergic asthma. Hum Immunol. 2003; 64:811-5.

Turton CWG, Morris L, Buckingham JA, Lawler SD,Turner-Warwick M. Histocompatibility antigens in asthma: populations and family studies. Thorax 1979; 34:670-9.

Ulrik CS, Backer V, Dirksen A. Mortality and decline in lung function in 231 adults with bronchial asthma: a ten year follow up. J Asthma .1992; 29:29-38.

Wang WX, Yang SZ, Chui XW, Zhang HL. Association of HLA-Bw 61 with asthma in the Chinese. Tissue Antigens.1988; 32:215-7. 
Wang C, Peng ZLi J et al.Comparative study of HLA-DRB1 allele in patients with chronic bronchitis and bronchial asthma.Zhonghua Yi Xue Yi Chuan Xue Za Zhi 1999; 16:371-3.

Wardaw AJ, Brightling C, Green R, Woltmann G, Pavord I. Eosinophils in asthma and others allergic diseases. Br Med Bull.2000; 56:985-1003.

Wenzel SE. Asthma: defining of the persistent adult phenotypes. Lancet.2006; 368:804-13.

Wide L, Bennich H, Johansson SGO.Diagnosis of allergy by an in vitro test for allergen antibodies. Lancet.1967; 2:1105-7.

White SR. Human leucocyte antigen -G: expression and function in airway allergic disease. Clin Exp Allergy.2012; 42:208-17.

Williams, H E, and Mc Nicol, K N. Prevalence, natural history and a relationship of whezzy bronchitis and asthma in children. B Med J .1969; 4:321-5.

Williams HC. Revised nomenclature for allergy for global use: report of the nomenclature review committee of the World Allergy Organization. J Allergy Clin Immunol. 2004; 113:832-6. 